\title{
10 Simulation of Solitary (Non-Apis) Bees Competing for Pollen
}

Jeroen Everaars and Carsten F. Dormann

\section{CONTENTS}

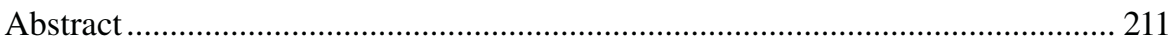

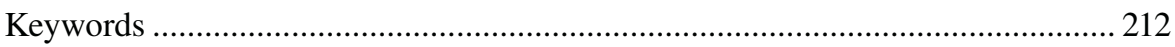

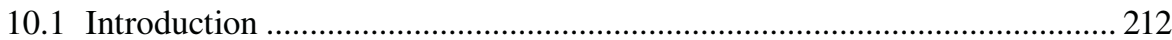

10.2 Simulation Model for Pollen-Foraging Solitary Bees in a Spatially

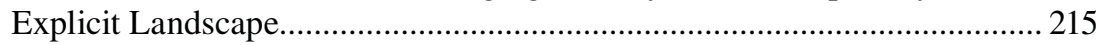

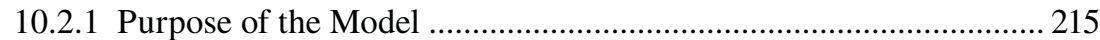

10.2.2 Entities, State Variables, and Scales ................................................... 216

10.2.2.1 State Variables of the Landscape (Environment and Spatial Units) ............................................................ 216

10.2.2.2 State Variable of the Bees (the Individuals)........................ 216

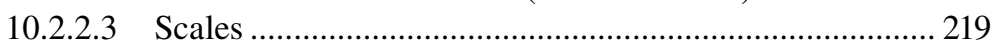

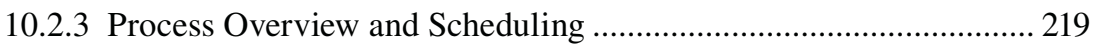

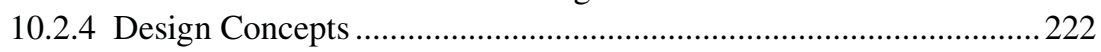

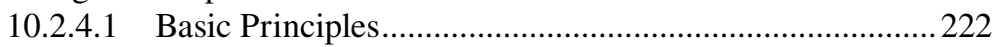

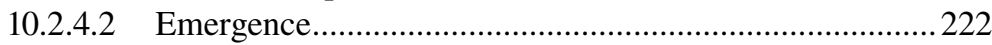

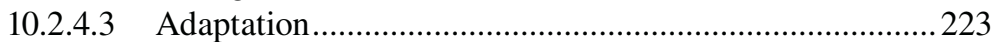

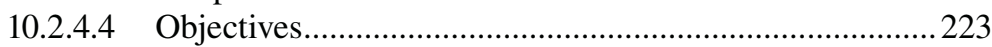

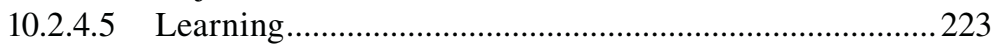

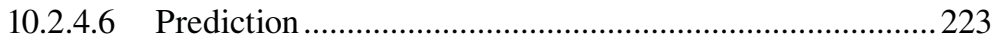

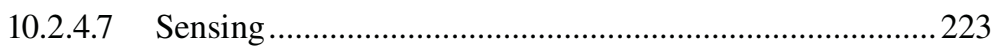

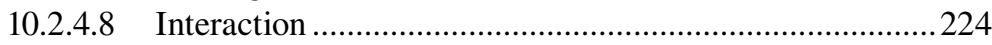

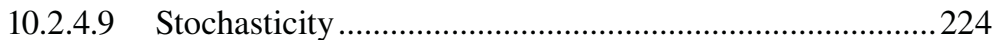

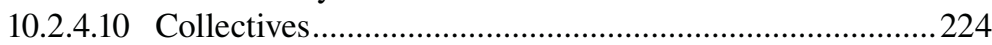

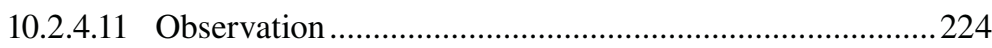

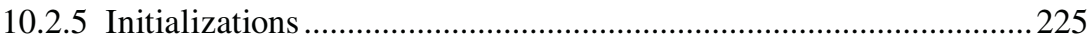

10.2.5.1 Landscapes and Habitat ....................................................225

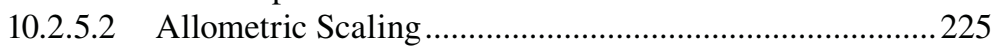

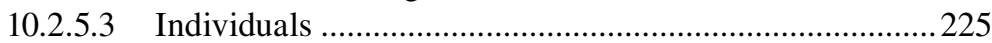




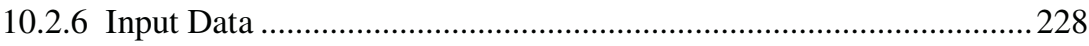

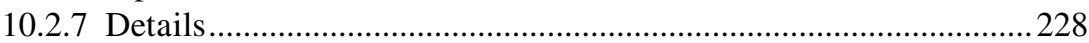

10.2.7.1 Landscapes and Habitat and Boundary Conditions.........228

10.2.7.2 Patch Leaving Rules and Flower Encountering ...............228

10.2.7.3 Determination of the Maximum Distance Allowed to Fly on a Foraging Trip (Distance of Certain Return) ......229

10.2.8 Pattern-Oriented Modeling.............................................................230

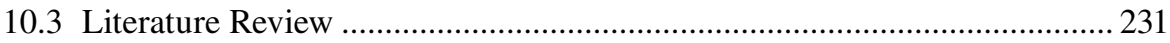

10.3.1 Natural Parameter Ranges, Extremes, and Common Values ............ 231

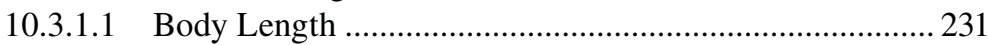

10.3.1.2 Landscape Element Size .................................................... 231

10.3.1.3 Flower Density, Pollen per Flower, and Pollen Availability.....................................................................223

10.3.1.4 Landscape Quality for Bees.................................................233

10.3.1.5 Pollen per Brood Cell and Pollen Capacity per Bee........234

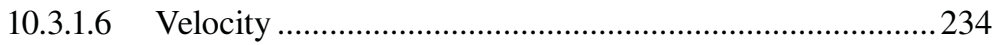

10.3.1.7 Flower Handling Time .....................................................234

10.3.1.8 Perception Distance and Length of Flight Units ..............236

10.3.1.9 Flower Memory, Habitat Cell Memory, and Ignorance.......236

10.3.1.10 Flight Path Tortuosity ........................................................237

10.3.1.11 Time at the Nest and Foraging Time ..............................2237

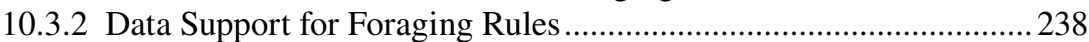

10.3.2.1 Five Behavioral Modules .................................................238

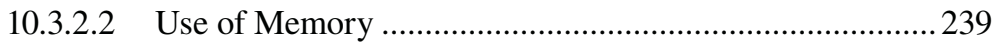

10.3.2.3 Within-Patch (Grid Cell) Foraging Behavior

(Behavior 1: Forage Flowers) ............................................240

10.3.2.4 Patch Selection (Behavior 2: Neighboring Cell) ...............240

10.3.2.5 Nest Clumping for Soil-Nesting Bees................................240

10.3.3 Exploration of Field Data for Response Variables............................. 241

10.3.3.1 Number of Brood Cells...................................................... 241

10.3.3.2 Foraging Trip Duration ...................................................... 241

10.3.3.3 Flowers Visited and Flowers Visited per Trip .................. 241

10.3.3.4 Mean Distance from Nest and Realized Foraging Range......242

10.4 Examples of Simulation Experiments ......................................................242

10.4.1 Foraging for Pollen: Competition Processes in Time........................245

10.4.1.1 Number of Brood Cells......................................................24

10.4.1.2 Number of Flower Visits.................................................246

10.4.1.3 Normal Foraging Activity and Far Foraging Activity .....247

10.4.1.4 Expansion over the Foraging Habitat..................................247

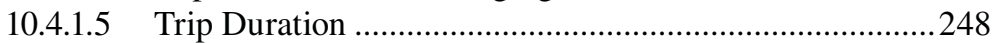

10.4.1.6 Time Budget Scenarios ....................................................249

10.4.1.7 How Well Does the Model Represent Foraging

Solitary Bees in Real Systems?...........................................249

10.4.2 What Do Extreme Parameter Values Imply for Solitary Bees?

A Global Sensitivity Analysis..........................................................250

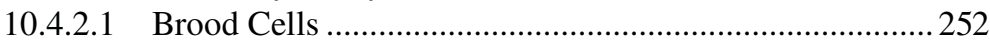


10.4.2.2 Flowers Visited ........................................................ 252

10.4.2.3 Foraging Habitat Visitation........................................... 252

10.4.2.4 Mean Distance Flown ................................................... 253

10.4.2.5 Conclusions from the Second Simulation Experiment .... 253

10.4.3 Which Body-Size-Related Traits Affect Foraging Behavior

Most Strongly?.

10.4.3.1 Importance of the Bee's Behavioral Traits in

Different Situations .....................................................254

10.4.3.2 Parameter Robustness of the Bee's Behavioral Traits .....254

10.4.4 How Much Do Landscape-Related Parameters

Affect Solitary Bees?.......................................................... 257

10.4.4.1 Importance of Landscape Characteristics ..................... 257

10.4.4.2 Parameter Robustness of Landscape Characteristics ...... 257

10.5 Understanding How Solitary Bees Interact with the Landscape..................258

10.5.1 General Conclusions ................................................................. 258

10.5.2 General Interest and Limitations ............................................... 259

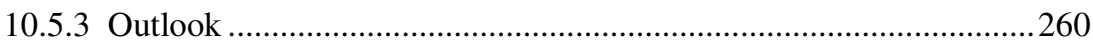

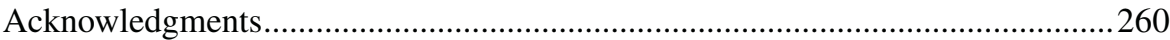

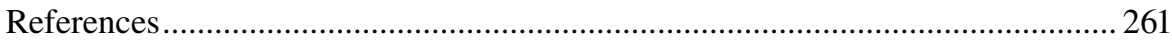

\section{ABSTRACT}

Bees are important pollinators, but both honey bees and wild bees are rapidly declining. One of the drivers for the decline of wild bees is land-use change, which affects the field mosaic and the fragmentation of the landscape. There is no general consensus in the literature about how wild bees respond to landscape configuration. Up to now, there are no simulation models that compare the performances of different solitary bees at the landscape scale. Body-size-related traits affect individual foraging behavior. We have therefore developed a spatially explicit individual-based simulation model, SOLBEE, with different bee traits and behavioral rules, which mimics the behavior and movement of pollen-collecting solitary bees. The model landscape is a square kilometer in size and consists of many patches with foraging habitat (varying amount) separated by inhospitable matrix (varying fragmentation levels). The foraging habitat has patch attributes such as flower density and minimum patch size. The bees differ in size (and in derived foraging traits such as velocity), nesting preference, and nest location. The system is further characterized by a timeframe of a single foraging day (with time steps of $1 \mathrm{~s}$ ) in which bees forage and compete with each other for pollen. Bee numbers (and density within the landscape) are scaled with present foraging resources and body size. During the day, these central-place foragers displace pollen from flowers (distributed over a mosaic of patches) to their nest. The main goal is to compare how bees perform in terms of fitness (brood cells) and pollination services (number of flowers visited, foraging habitat visitation, and foraging distance) within a foraging day. Parameterization of the model input is mainly based on literature review, and the model's rule behavior was improved with a pattern-oriented approach.

In several examples, we present four simulation experiments to investigate parameter effects and parameter sensitivity (Section 10.4). We show that the model 
produces realistic foraging behavior progressively during the foraging day and that the responses overlap well with values from the literature. This can be considered as a validation with the exception that model bees were found to be somewhat more efficient than real bees, yielding higher numbers of brood cells. A global sensitivity analysis of the parameters in their biological range revealed that the amount of pollen per flower (i.e., flower size) most influenced the number of brood cells and foraging habitat visitation. Body size was the dominant parameter for the number of visited flowers and the mean flown distance. The remaining two simulation experiments showed that the model can be considered robust against small changes $(10 \%$ change in parameter value). The parameters that affected the responses here most were handling time per flower from the bee-related parameters and the amount of pollen per flower and pollen limitation (dispensing mechanism of the flower) from the landscape-related parameters. The simulation experiments yielded basic understanding of the model. Time constraints are more important for solitary bees than foraging resources, as they affect wood-nesting bees, which nest at field edges, more than soil-nesting bees.

\section{KEYWORDS}

Individual-based model (IBM), Solitary bees, Pollen foraging, Resource competition, Body size

\subsection{INTRODUCTION}

The honey bee (Apis mellifera) is the single-most important pollinator in the world [1]. However, the world counts about 20,000 wild bee species that are good pollinators as well [2]. Solitary bees are the largest subgroup of wild bees with about 14,000 species worldwide [3]. They live solitary and have a wide range of different food preferences, nest preferences, and behavioral traits (Figure 10.1). They differ considerably from eusocial and semisocial bees in foraging behavior (see, e.g., [4-6]). Communication between eusocial bees can lead to near-optimal foraging [7,8], while solitary bees do not communicate about foraging patches. Solitary bees forage alone and therefore deal with limited knowledge of resource locations and their quality. While eusocial bees spend a large part of their time foraging for nectar, solitary bees focus on the collection of pollen for their offspring [9]. Evidently, "bee," "honey bee," "flower visitor," and "pollinator" cannot be used as synonyms [10].

Pollination is essential for many wild plants and human food crops. The rapid worldwide decline of honey bees and wild bees [11,12] has alarmed conservationists and politicians to take action to reduce pollinator losses [13]. The 2010 target to reduce the rate of biodiversity loss has not been met, despite increasing political effort to protect biodiversity [14]. The contribution of honey bees to crop pollination may have been overestimated $[15,16]$, and protecting natural habitat near crop fields seems to be a key solution in providing natural pollination services (see, e.g., [16-19]). In agricultural areas, habitat management for maintaining wild pollinator populations in the landscape can be a cost-effective way of securing crop pollination, especially when honey bees are decreasing [20]. 


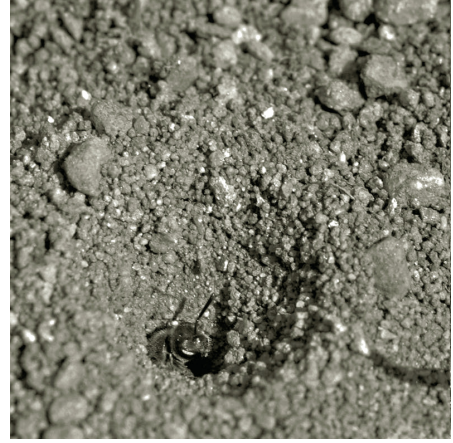

(a)

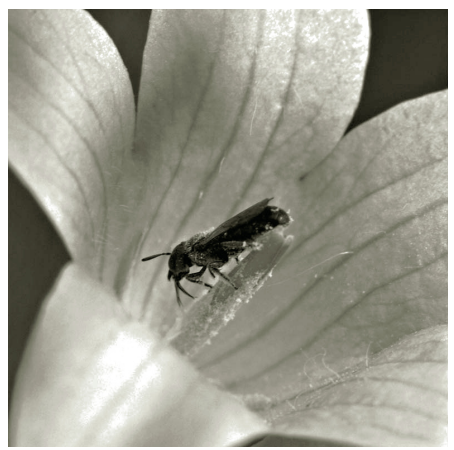

(c)

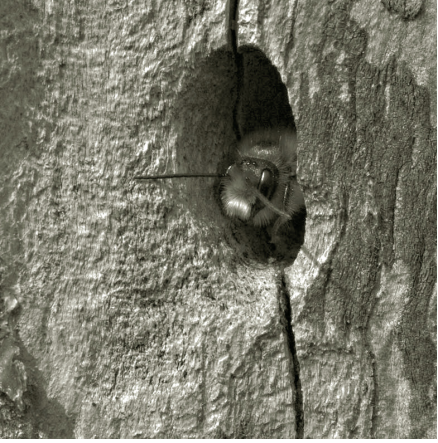

(b)

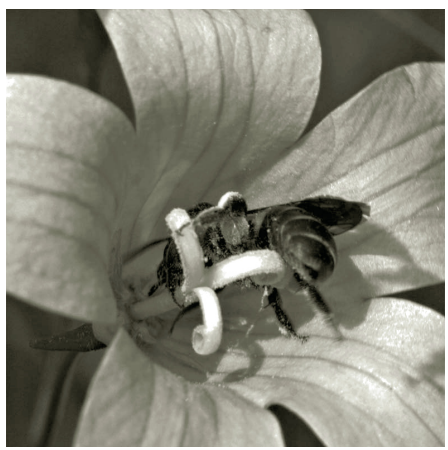

(d)

FIGURE 10.1 Solitary bees are a large group of pollinators with different traits including body size and nesting preference. They share the same foraging resources. (a) A small soilnesting solitary bee. (b) An intermediate-sized wood-nesting solitary bee. (c) A small solitary bee foraging for nectar and pollen on Campanula patula. (d) An intermediate-sized solitary bee foraging for nectar and pollen on Campanula patula. (Photo by J. Everaars.)

Agriculture is probably the largest threat for wild bees. Increased land use for agriculture leads to habitat fragmentation and loss of bee habitats and seems to be the most important driver of wild pollinator losses [21,22]. There is a consensus on how honey bee colony losses can be reduced [23,24], but defining how agriculturally dominated landscapes can be optimized for wild bees is more complex [18]. Many authors underline the need for a better mechanistic understanding of the effect of landscape configuration on wild bees in order to estimate the importance of habitat loss and fragmentation, to estimate the effects of land use on pollination services, and to support management decisions [12,25-29]. Body size and nesting preference affect the response to landscape features and fragmentation, but, up to now, no systematic exploration exists. Body size (comprising a wide range in solitary bees) affects traits such as the bee's velocity or capacity for carrying pollen (Figure 10.2). These traits influence the response of bees to landscape structures [30]. Models can help understanding how bees perform in patchy landscapes. 

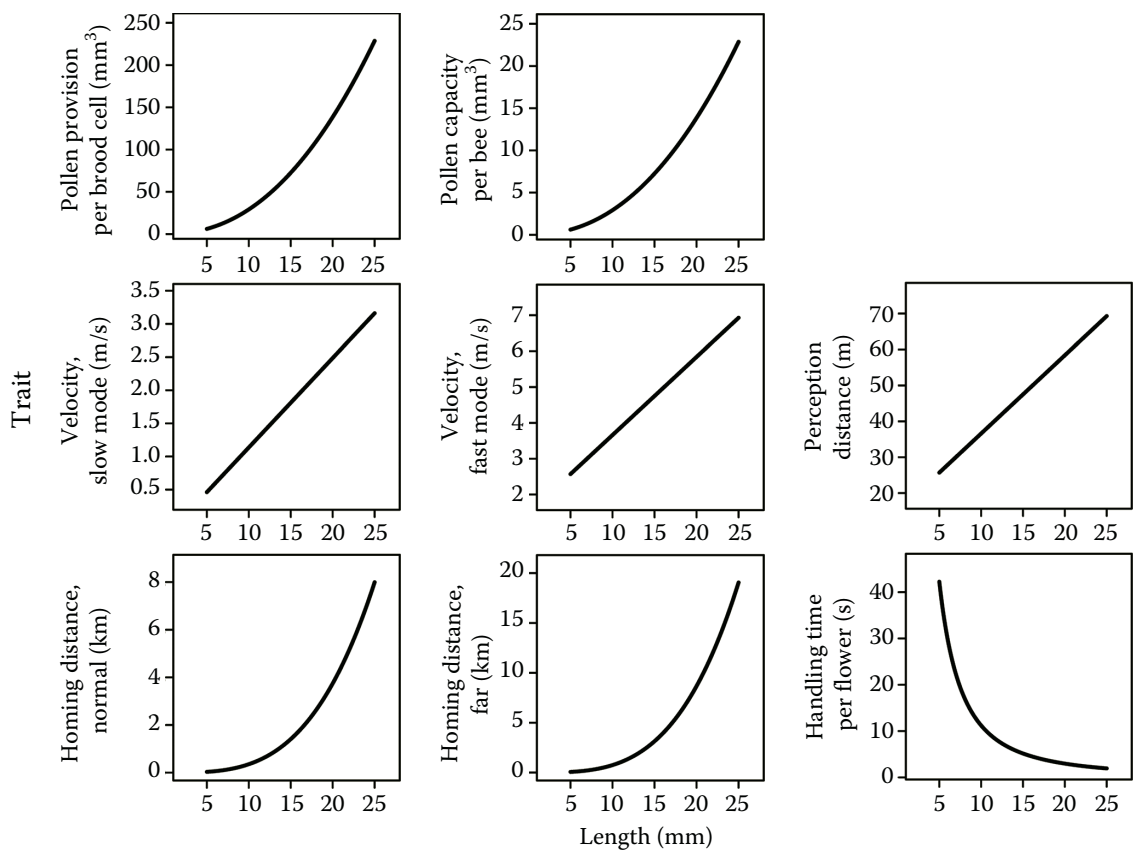

Body size

FIGURE 10.2 Effect of body size on different traits that affect the foraging behavior of solitary bees. Equations and references are given in Table 10.3.

Existing models with pollinators are of limited value for understanding the interaction between solitary bees and landscape structure. Data-based approaches include only little biological detail (see, e.g., [31,32]). A few recent models included more biological realism. One model considered solitary foragers with limited memory rather than communicating eusocial bees [33]. Another study estimated field-to-field gene flow of crops by moving bumblebees based on experimental data [34]. A relatively detailed model did include local resource competition in space, bee size, and spatial configuration of patches, but focused on eusocial honey bees only [35].

No model has yet considered active pollen foraging as the main driver of pollinator movement. The existing models additionally lack several of the following components: comparison between different pollinators, partial habitats for nesting and foraging, differentiation between individuals, local competition, and size of the pollinator. Solitary bees are mainly foraging for pollen to provide their brood cells. Pollen differs from nectar in the sense that it does not replenish during the day. Solitary bees fly out alone from the nest, forage at the closest suitable flower patch, and return when they collect enough pollen and/or nectar. This typical behavior of solitary bees, which differs from eusocial bees, was the reason to develop a new model.

We developed a model with biological detail to study the interaction of wild bees with the landscape. We decided to use an individual-based, spatially explicit simulation model to simulate naive solitary bees that forage for pollen in the landscape. Time could be more constraining than energy for wild bees [36], and we therefore 
focused on differences in daily performance. The individual-based model (IBM, or agent-based model, ABM) is an established method for investigating animals in space and time, including solitary bees [37]. This kind of model allows us to include multiple traits (related to size and nesting preference, modeled as functional types) that determine movement and decision rules and lead to realistic depletion of pollen in space and time. Minimalistic approaches with only home-range descriptions cannot account for local competition processes [38]. IBMs with a high level of realism are often used in ecology and perceived as a welcome addition to the more theoretical approaches with a limited number of parameters [39]. In this chapter, we ask what foraging rules are required to simulate foraging behavior with body-size-related traits. At the test stage, we ask whether the model produces realistic foraging patterns in time and how well the response variables overlap with real systems. We also ask which parameters are most influential within biological parameter ranges and how sensitive parameters are against small changes.

\subsection{SIMULATION MODEL FOR POLLEN-FORAGING SOLITARY BEES IN A SPATIALLY EXPLICIT LANDSCAPE}

We describe here the model SOLBEE, a spatially explicit individual-based simulation model that mimics solitary bees in agriculturally dominated landscapes. Solitary bees forage for pollen individually without communication about food locations (in contrast to honey bees and bumblebees, which try to optimize foraging tasks by communicating). Our goal was to develop a mechanistic description of the pollinator-plant interaction at the landscape scale with relevant parameters. We implemented several body-size-related features that determine flight and pollen-collection behavior of the bees. The behavioral rules are implemented in an if-else format that is intuitive to follow. The landscape, with patches of flowering plants providing pollen to the bees, has several features from coarse-grained structures to fine-scaled pollen release per flower. We follow the standardized ODD (Overview, Design concepts, Details) protocol $[40,41]$ to describe our IBM. It provides overview, general concepts, and casespecific model details in such a way that a model becomes more reproducible.

\subsubsection{Purpose of the Model}

This rule- and individual-based model aims at understanding how wild bees with different life-history traits interact with landscape structure and providing insight into the bee's perspective of a landscape. It is designed to be generic and applicable to multiple solitary bee species, which are defined by parameters. Many of the bee's traits, and therefore behavior as well, are related to body size. Some traits improve performance with body size (such as velocity, handling time, and resource recognition distance), while others moderate their performance (such as required pollen for a single brood cell). We expect that bees of different size perform differently when they collect pollen in a spatially explicit environment. This may also be influenced by the spatial allocation of the resources. We compare fitness differences by simulating the behavior and time allocation of solitary bees that determine the amount of pollen brought to the nest. 


\subsubsection{Entities, State Variables, and Scales}

The model comprises a spatially explicit grid-based landscape with a given resource distribution and a community of pollen-collecting bees. Table 10.1 shows an overview of the system properties and their values.

\subsubsection{State Variables of the Landscape (Environment and Spatial Units)}

The landscape is described at two levels: at the coarse landscape level and the more detailed vegetation level (habitat units). We use for the first level a landscape generator, which enables the separation of habitat loss and fragmentation as different processes and allows for a wider range of foraging habitat availability and fragmentation than do images obtained from real land-use maps. Habitat availability (or loss) and fragmentation are focal variables for our simulations. The landscape is divided into habitat units that are either suitable or unsuitable for foraging. Agriculturally dominated landscapes are a mosaic of sharply contrasting habitat types [28]. Suitable habitat units (second level) are described by flower density, amount of pollen per flower, and the proportion of pollen that is available per pollinator visit (regulation of flower depletion). These different vegetation-level parameters serve the fine detail that is needed at the individual bee level (pollen uptake, flying between flowers) and represent homogeneous vegetation (fixed values). Auxiliary parameters describe the average distance between flowers and the initial amount of pollen for each habitat unit. We track the remaining pollen volume and the number of bee visits per grid cell during simulation.

\subsubsection{State Variable of the Bees (the Individuals)}

We consider six different types of solitary bees according to three body sizes (body length of 6,12 , and $24 \mathrm{~mm}$ ) and two nesting preferences. Each simulation deals with a bee population of one type. Several bee traits are directly calculated from body size with allometric scaling rules. These include pollen capacity, flight velocity, flower handling time, perception distance, length of flight units ("step-lengths"), and return distance (Tables 10.1 and 10.3). Several of the bee traits are unrelated to body size such as memory size, tortuosity of the flight path, patch-leaving thresholds, and the amount of time spent at the nest for nonforaging activities. In Section 10.3.1, we give an overview of the main parameters with biological ranges and simulated values, accompanied by explanation and references.

We implemented above-ground (wood and cavity) nesting and subterranean (soil) nesting as two distinct nesting preferences. Wood-nesting bees nest in our model at the border of foraging habitat with unsuitable habitat (i.e., field edges). Such habitat edges are often suitable for nesting in natural landscapes [30,42], since they provide shrubs and trees at nesting substrates. Soil-nesting bees nest in the soil at bare spots in the vegetation and nest in our model in aggregations everywhere in the foraging habitat. The nesting preference in our model has consequences for the spatial distribution of bees. Each bee has a fixed start location (nest) to which it must return (central-place foraging).

Six different bee types were selected to represent a wide range of bee genera in nature: soil-nesting small bees $(6 \mathrm{~mm})$ : Dufourea, some bees from Halictus and 


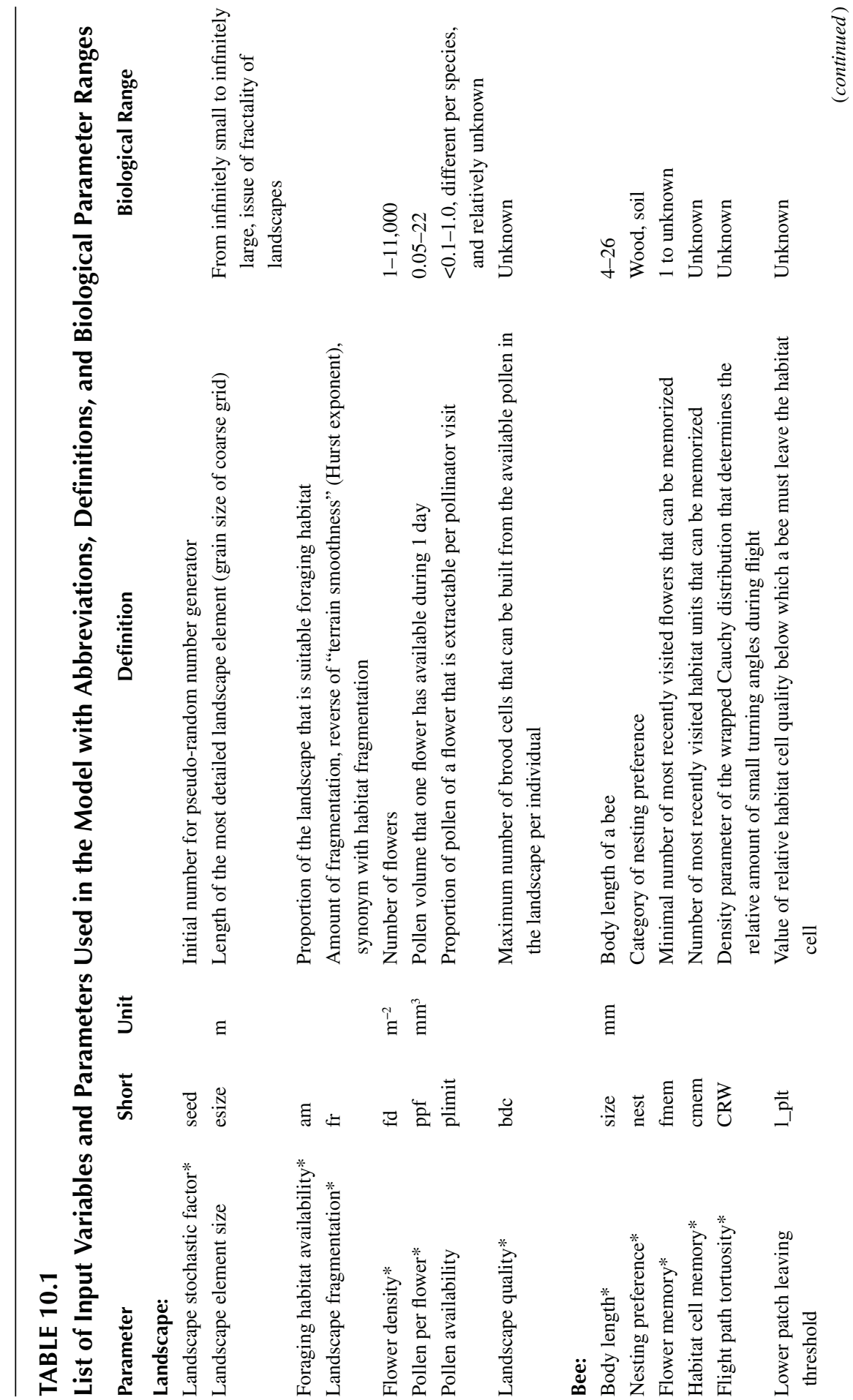




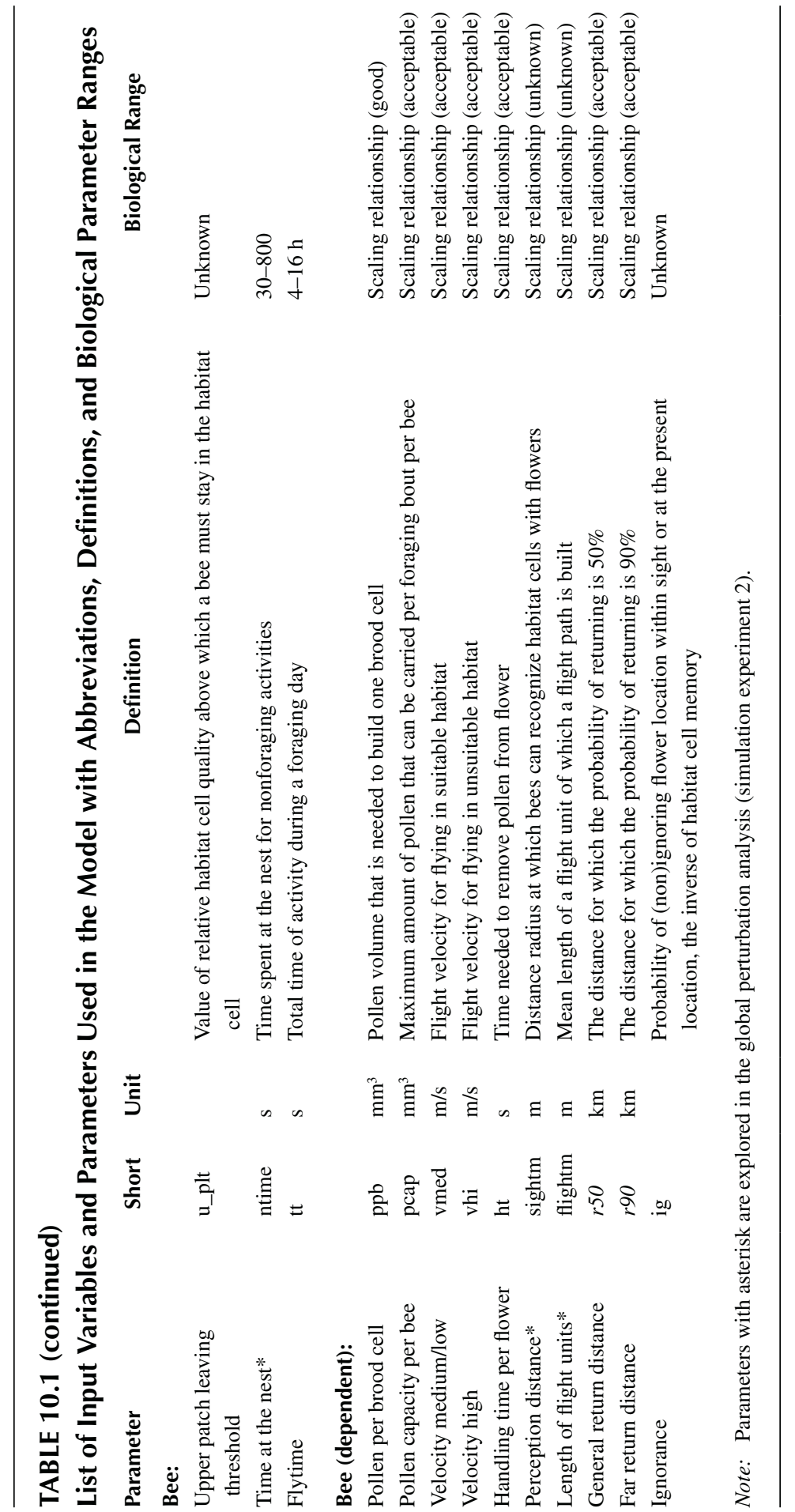


Lasioglossum; soil-nesting medium-sized bees (12 mm): most bees from Andrena, Anthophora; soil-nesting large bees (24 mm): Centris, Eulaema, Oxaea, Habropoda, Xenoglossa; wood-nesting small bees (6 mm): Ceratina, Chelostoma, Heriades, Hyleaus; wood-nesting medium-sized bees (12 mm): several Osmia, Megachile; wood-nesting large bees (24 mm): Xylocopa.

Different state variables are recorded for each foraging trip (used synonymously with foraging bout) for each bee: pollen collected during the trip, distance from the nest, number of unsuccessful and successful flower visits per trip, most recently visited locations, quality of last visited location, flight direction, start time of the foraging trip, and "future time" to schedule the next behavioral element and current spatial location. Data of different foraging trips is collected at the nest; here we record (per bee) the number of returns to the nest, pollen delivered to the nest, number of flowers probed, maximum distance from the nest, and time spent per behavioral module. Other auxiliary variables keep track of the total distance flown and trip duration. At the end of the simulation, the mean amount of pollen collected per bee is converted into the (size-related) number of brood cells. We do not use population-level variables.

We link the landscape and the bee population with a parameter that describes the overall landscape quality for bees, which is used for calculating the total number of bees in the landscape (section initializations).

\subsubsection{Scales}

The simulated landscapes have a spatial extent of $1 \mathrm{~km}$, because solitary wild bees respond to landscape structures on scales up to $1,000 \mathrm{~m}$ [43]. We used a grain size of $50 \mathrm{~m}$ that mimics raster-based land-use maps and is used in landscape-scale studies with solitary bees $[44,45]$. Lower grain sizes result in very fragmented, grainy landscapes that do not realistically represent agriculturally dominated landscapes. However, bees perceive landscape structures in more detail [29] especially nesting substrate in strips with shrubs and trees [46] and on small tree islands [47]. Bees show differences in behavior at a fine scale (see, e.g., $[48,49])$. We therefore subdivided the landscape maps into $5 \times 5 \mathrm{~m}$ cells. Our model landscapes thus consist of 200 by 200 grid cells. From the perspective of the bee, the landscape contains foraging habitat and matrix. The foraging habitat is split up into edge (5 $\mathrm{m}$ wide strips, which woodnesting and soil-nesting bees use for nesting and foraging) and interior (used for foraging by both bee types and for nesting by soil-nesting bees only).

Our model landscape has reflecting rather than absorbing boundaries, because we deal with central-place foragers that have to return to their nests. Consequences of this implementation are discussed under "Details" (Section 10.2.7). We use 14,400 time steps of $1 \mathrm{~s}$, which equals a foraging period of $4 \mathrm{~h}$. A behavioral unit of a bee lasts from 1 to several seconds. The decision of the exact time horizon is based on a tuning with the time spent at the nest, which is discussed in simulation experiment 1 (Section 10.4).

\subsubsection{Process Overview and Scheduling}

After the initialization phase, in which a landscape is generated, a bee community is defined (bee traits regulated by allometric scaling, see Section 10.2.5). 
A nest site is assigned to each individual, upon which a foraging day starts. The virtual bees exhibit five types of behaviors. The behavior of one individual is strictly sequential in time and lasts at least for $1 \mathrm{~s}$ (discrete time steps). When an individual performs a behavioral type, state variables are changed. When a behavioral type lasts longer than $1 \mathrm{~s}$, a waiting time is set for that individual. Individuals are processed in random order at each time step (Figure 10.3a). Waiting times imply asynchronous updating of individuals. When a foraging day is completed, values are averaged per bee and written to an output file.

These behavioral modules are performed in a loop until a certain foraging time (flytime) is completed after which all activities are stopped instantaneously (fair comparison between bees) and values are averaged per bee and written to an output file. During behaviors 1, 3, and 4, bees leave visitation marks in the landscape, which are used as a measure of pollination potential in the later analysis. Time penalties for each bee are given in Table 10.2.

The five behaviors are as follows (Figure 10.3b):

1. Forage Flowers (Forage Flowers within a Landscape Grid Cell): A bee flies from flower to flower directly (spatially implicit), encounters stochastically a full or empty flower (based on present resources), collects pollen, and decides about leaving the grid cell. Behavioral states can change into fly around (3) (current resources very low) and neighboring cell (2) (current resources low), or fly back (4) (enough pollen collected).

2. Neighboring Cell (Fly to a Suitable Neighboring Landscape Grid Cell): The bee considers the eight neighboring landscape grid cells for foraging. It accepts one of them randomly when it contains flowers and if it has not been visited recently. The behavioral state changes back to forage flowers (1) after moving there. On rejection of all eight cells, the behavioral state changes into fly back (4) (far from the nest) or into fly around (3).

3. Fly Around (Fly Around and Look for Unknown Foraging Areas): The bee performs a correlated random walk (changes direction and moves one step). The behavioral state changes to forage flowers (1) if either the new landscape grid cell is suitable (contains flowers and has not been visited recently) or if a suitable landscape grid cell has come within sight (move second step) or it can change into fly back (4) (too far from the nest). With a certain probability, suitable cells are ignored, leading to a more realistic foraging behavior (better matrix crossing and better foraging of interior habitat; see Section 10.2.8).

4. Fly Back (Fly Back to Nest): The bee performs a directed random walk (correlated random walk in the direction of the nest). Eventually, the state changes into nest reached (5).

5. Nest Reached: The bee delivers the pollen to the nest and spends time on nonforaging activities (while other bees still deplete the landscape). Afterward the behavioral state is set to forage flowers (1). 


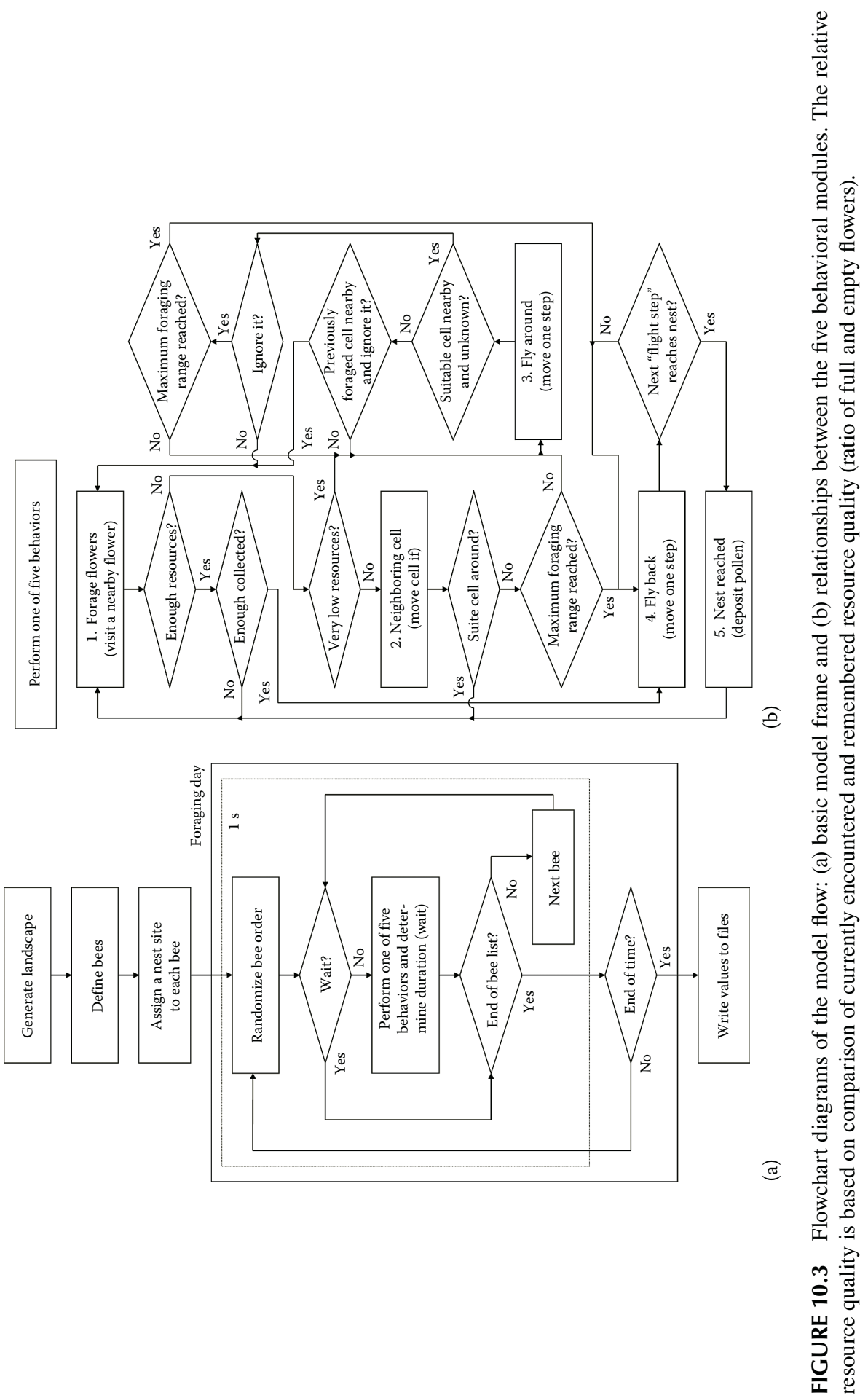




\section{TABLE 10.2 \\ Overview of Time Penalties}

\begin{tabular}{|c|c|c|}
\hline Behavior & Time Penalties for & Value (Minimal $1 \mathrm{~s}$ ) \\
\hline \multirow[t]{6}{*}{ 1. Forage flowers } & Poor habitat grid cell: & \\
\hline & - Assessing patch quality & $1 \mathrm{~s}$ \\
\hline & Good habitat grid cell: & \\
\hline & - Flying to a flower & Based on medium/low velocity (size) \\
\hline & $\begin{array}{l}\text { Full flower: removing pollen } \\
\text { from a flower }\end{array}$ & Based on handling time (size) \\
\hline & - Empty flower: assessing flower & $1 \mathrm{~s}$ \\
\hline \multirow[t]{2}{*}{ 2. Neighboring cell } & $\begin{array}{l}\text { Accepting or denying a } \\
\text { surrounding cell }\end{array}$ & $1 \mathrm{~s}$ \\
\hline & - Flying to a surrounding cell & Based on medium/low velocity (size) \\
\hline 3. Fly around & - Distance flown per flight unit & Based on high velocity (size) \\
\hline 4. Fly back & - Distance flown per flight unit & Based on high velocity (size) \\
\hline 5. Nest reached & $\begin{array}{l}\text { Pollen deposition and other } \\
\text { nonforaging activities }\end{array}$ & $30 \mathrm{~s}$ (parameter time at the nest) \\
\hline
\end{tabular}

Note: More details on the selection of values can be found in Section 10.3.2.

\subsubsection{Design Concepts}

\subsubsection{Basic Principles}

We use several known foraging principles such as area-restricted search for resource items [8] and a patch "giving up time" [50]. Area-restricted search means that the animal has a limited knowledge and memory of the environment and assesses the local environment with a fixed-sized search window and inevitably chooses close resource points [8]. The decision of an individual to leave a patch is based on actually probed flowers and the estimated resource level, rather than by time spent in a patch. Resource-based "departure rules" may be more realistic than time-based ones [8], and we used resource ratios and thresholds to determine departure [51]. In a spatially explicit IBM, this means that bees react to the rapidly changing resource levels caused by other foraging individuals. We use the concept of "near-far search" as an optimization that is relevant in large patchy environments [52]: bees generally forage on nearby flowers, but switch to foraging resources farther away when nearby resource levels get low. Such behavior has been shown for solitary bees [44,53]. Not-considered concepts that are known for nectar-foraging honey bees or bumblebees include "majoring and minoring" [54], the "matching law," and the "ideal free distribution" [33], because they are not likely to apply to oligolectic (foraging on one plant species) pollen-foraging solitary bees. We do not explore or compare the used principles; they only serve to achieve realistic foraging behavior.

\subsubsection{Emergence}

Complex behavior of bees emerges from five behavioral rules, posing differences on individuals during simulation (i.e., different behaviors coexist). Differences in 
nest positions (and bee densities) cause differences in local competition for foraging resources. The amount of pollen collected (or number of brood cells), the mean distance flown from the nest (or foraging distance), and the number of flowers visited are not coded into the model. Also a spatial "visitation map" emerges from behavioral rules and landscape structure and is used to calculate the percentage of the foraging habitat that has been visited by a bee community.

\subsubsection{Adaptation}

The individuals adapt to changing local resource conditions. After visiting and memorizing the status of a predefined minimal number of flowers (flower memory), the habitat cell quality (ratio of full to empty flowers encountered) is compared with the quality of the last visited habitat grid cell. According to the relative quality and an upper and lower patch-leaving threshold, a bee stays (relative quality better than upper patch-leaving threshold) or leaves.

\subsubsection{Objectives}

We measure the performance of an individual by how much pollen it can collect within a fixed time span. The costs consist of time penalties for each behavioral rule (Table 10.2). The amount of pollen collected at the nest is eventually converted to a number of brood cells according to body size. For solitary bees, efficiency (and hence fitness) can be formulated as "potential number of offspring produced from the pollen per unit time on the flower" [55], represented in the model by the number of brood cells.

\subsubsection{Learning}

The behavioral rules are static without a learning component (the same conditions in later foraging trips lead to the same decisions), because solitary bees are considered primitive foragers and display less efficient behavior than honey bees [56]. The memory of the bees is used for memorizing locations and quality and changes constantly (limited memory), but application of this memory is not optimized by learning. The sequence of behavioral modes and the outcome of decisions change with time as a result of local depletion of flowers and patches.

\subsubsection{Prediction}

The individuals cannot predict any future condition, except for the fact that they memorize recently visited habitat cells and avoid them because they predict that food conditions are low there.

\subsubsection{Sensing}

During foraging, bees assess neighboring landscape grid cells for suitable foraging habitat (resource availability) by vision and remember if they have visited them recently. When flying through unsuitable matrix, they assess the environment with a square-shaped search window. Furthermore, they sense the distance to the nest and can fly back anytime when they are too distant. The bees do not sense each other and therefore experience local competition only indirectly. 


\subsubsection{Interaction}

Interaction between individuals exists indirectly through competition for resources. Local competition is expected to be highest around the nest, where resources are depleted first. Since the nest location is determined by landscape structure and nesting preference, the magnitude of interaction differs between landscapes, bee types, and within a simulation in space and time.

\subsubsection{Stochasticity}

We use stochasticity for different goals:

1. To generate landscapes: The fractal algorithm is partly based on stochastically generated noise.

2. To randomize the sequence and decisions of bees: We randomize the sequence of individuals at each time step, assign a random direction at the start of the foraging trip, choose randomly from suitable habitat cells around, and choose randomly when there are more "nearest locations" within sight.

3. To produce natural variability in behavior and nesting: Natural variability is a major element of the correlated random walk (wrapped Cauchy distribution for turning angles and a normal distribution for flight unit lengths) and different leaving thresholds. Nest sites are selected randomly. A landscape grid cell is drawn randomly until one is suitable for nesting according to different nesting preferences. Furthermore, we use specified frequencies (or a specified fraction) for ignoring suitable habitat grid cells, for determining the binary full or empty status of a flower, for clumping of nests (soil-nesting bees), and for the probability distribution of maximum return distances. In specific cases, we use stochasticity for rounding to integers (when the frequency distribution between two is not uniform).

\subsubsection{Collectives}

We do not use collectives in our model. Each bee forages solitarily without direct interaction with other bees.

\subsubsection{Observation}

We record bee performance for each individual as total pollen collected, realized and mean foraging range (distance flown from the nest), number of returns to the nest, and mean trip duration. For each behavioral module, we record the amount of time spent in it. As output variables, we use the arithmetic mean over all individuals and the standard deviation. At the landscape level, we record the total number of flower visits and visitation marks (grid cells visited, including those without flowers). From these visitation marks, we calculate the percentage of seminatural habitat that was visited. We record the number of flower visits per bee, as indicator for how the pollen vector behaves (but not as an indicator of the performance of the bee, because here we do not distinguish between full and empty flowers). 


\subsubsection{INITIALIZATIONS}

\subsubsection{Landscapes and Habitat}

We use "noise" from a random number generator (landscape stochastic factor) and a Hurst exponent for fractional Brownian motion (landscape fragmentation) and a threshold (foraging habitat availability) to generate a landscape [57]. We generate landscapes symmetrically and wrapped [58]. Symmetry prevents the entire foraging habitat to be in one corner, and wrapped boundaries give the landscape the appearance to be part of a larger landscape.

Suitable habitat cells are assigned an initial pollen volume based on flower density and pollen per flower. We do not assess a range of landscape metrics for the landscapes, because most landscape metrics are highly correlated in artificial landscapes [59]. Instead, we calculate the proportion of available nest habitat (landscape grid cells suitable for nesting) according to the nesting preference of the bee.

\subsubsection{Allometric Scaling}

The bee traits relating to body size were calculated by allometric rules based on the initial body length (Table 10.3). In order to use allometric relationships from literature, we first converted body length to intertegular span - the shortest linear distance between the wing tegulae [60] — and to dry body mass (data taken from [61]). Several traits are directly based on the literature (pollen per brood cell, general return distance, far return distance), while others were calculated from data from multiple studies (velocity medium/low, velocity high, handling time per flower). We use these parameters subsequently to calculate pollen capacity per bee, perception distance (and perception area), and length of flight units (Table 10.3).

A more complex allometric trait is the maximum distance per foraging trip, based on homing distance. Homing distance can be considered as the maximum distance with knowledge of the environment, which differs between individuals and in different directions. Allometric scaling of homing distance of bees is known for typical homing distance $(r 50)$ and far or maximum homing distance $(r 90)$ from the literature [62]. We connect these two parameters by a saturation curve (Table 10.4) after calculating a shift parameter, which represents a certain minimal knowledge (see Section 10.3.2 for more details). Within this minimal distance from the nest, bees return only with a full pollen load.

\subsubsection{Individuals}

We assume our bee community to be in equilibrium with the amount of foraging resources. In natural communities, bee density is often related to flower cover [30,63] or flower diversity [64,65]. We used pollen volume as resource parameter [61] and scaled the number of individuals to the total amount of pollen present in the landscape. More specifically, the total number of individuals is calculated by dividing the pollen volume present in the landscape by the pollen volume available per individual (Table 10.4). The latter is calculated with the help of the parameter $b d c$ (bee density control or landscape quality for bees) as the "potential offspring (brood cells) per individual." We set this value at 30 , which means that each bee can potentially build 


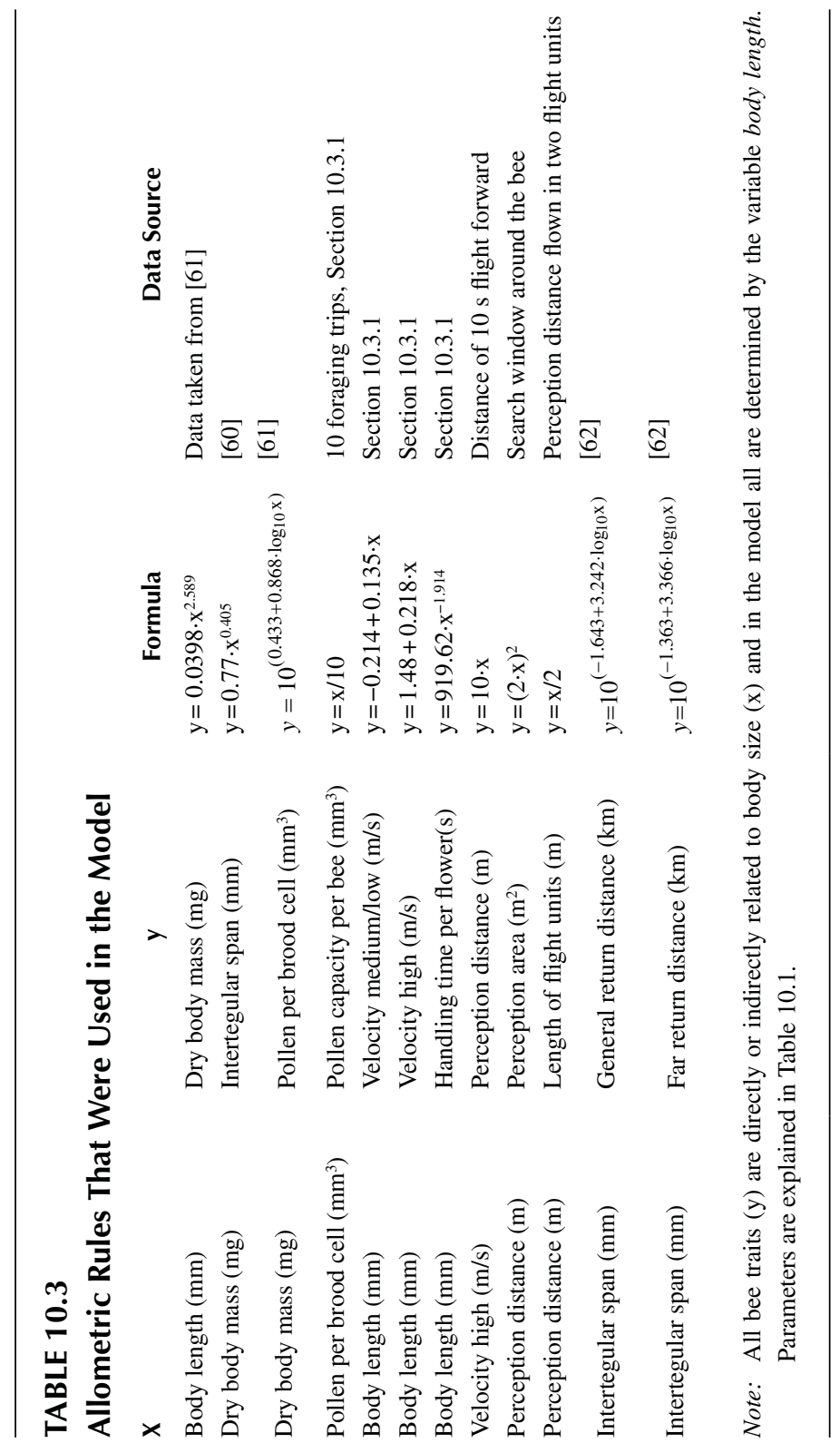


TABLE 10.4

\section{Body-Size-Based Calculation of Individuals and Maximum Flight Distance on a Foraging Trip}

\begin{tabular}{|c|c|c|c|c|}
\hline & Multiple x & Calculation of & Formula & Notes \\
\hline A & $\begin{array}{l}\text { Foraging habitat } \\
\text { availability (am), } \\
\text { landscape area, } \\
\text { flower density }(f d), \\
\text { pollen per flower } \\
\text { (ppf), landscape } \\
\text { quality (bdc), pollen } \\
\text { per brood cell (ppb) }\end{array}$ & Individuals & $\begin{array}{l}(a m \cdot \text { total area } \\
f d \cdot p p f) / \\
(b d c \cdot p p b)\end{array}$ & $\begin{array}{l}\text { Pollen volume available } \\
\text { to the entire bee } \\
\text { community (numerator) } \\
\text { and the pollen volume } \\
\text { available to one bee } \\
\text { (denominator) are } \\
\text { calculated in } \mathrm{cm}^{3} \text {. The } \\
\text { total area is } 1 \mathrm{~km}^{2}\end{array}$ \\
\hline B & $\begin{array}{l}\text { General return } \\
\text { distance (r50), far } \\
\text { return distance } \\
\text { (r90), distance from } \\
\text { the nest }\end{array}$ & $\begin{array}{l}\text { Probability (of } \\
\text { reaching a distance } \\
\text { from the nest without } \\
\text { knowledge of the } \\
\text { environment, homing } \\
\text { ability) }\end{array}$ & $\begin{array}{l}(\text { Distance-shift }) / \\
(\text { Km }+ \text { distance- } \\
\text { shift })\end{array}$ & $\begin{array}{l}\text { Shift }=1.125 \cdot r 50 \\
-0.125 \cdot r 90 \\
K m=r 50+\text { shift }\end{array}$ \\
\hline $\mathrm{C}$ & & $\begin{array}{l}\text { Maximum distance } \\
\text { from nest (allowed to } \\
\text { fly per foraging trip) }\end{array}$ & $\begin{array}{l}(\mathrm{U} \cdot \mathrm{Km} / \\
1-\mathrm{U})+ \text { shift }\end{array}$ & $\begin{array}{l}\text { Inverse of distance } \\
\text { probability; } \mathrm{U} \text { is drawn } \\
\text { from a uniform } \\
\text { distribution }\end{array}$ \\
\hline
\end{tabular}

Note: Row labels (A-C) are used in the text.

30 brood cells from the amount of pollen in the landscape independent of its size (equal performance potential for all bees). A large value means fewer bees, but also a higher landscape quality per bee. The value chosen (see Section 10.3.1 for a short review) results in realistic bee densities in the landscape with high bee numbers for small bees and lower numbers for large bees and an increase with increasing foraging habitat. A disadvantage of this approach is that model runtime varies several orders of magnitude for different parameter settings (body length and foraging habitat availability as well as flower density and pollen per flower).

Each simulation uses one bee type (according to size and nesting preference), and the initially calculated number of individuals remains constant during simulation (one foraging day without population dynamics). Each individual has several initializations. The most important is the nest assignment, which is, in the model, always near foraging resources [66]. Wood-nesting bees accept a (randomly chosen) location to nest when it is at the edge of the foraging habitat, and soil-nesting bees accept a location all over the foraging habitat but preferably in the vicinity of another bee nest in the soil (see Section 10.3.1 for details). Nest distribution depends thus directly on landscape configuration. Each bee was additionally initialized with a random direction (used in the behavior fly around) and a maximum distance (knowledge of the environment). 


\subsubsection{InPUt Data}

The model does not use time-varying input data [41].

\subsubsection{Detalls}

Here we describe several implementation details and discuss the considerations leading to implementation decisions. Data-based selection of foraging rules and parameter values follows in separate Sections 10.3.1 and 10.3.2.

\subsubsection{Landscapes and Habitat and Boundary Conditions}

We use "noise" from a random number generator (landscape stochastic factor) and a Hurst exponent for fractional Brownian motion (landscape fragmentation) and a threshold (foraging habitat availability) to generate a landscape with the midpoint displacement algorithm [57]. In short, this algorithm creates a three-dimensional surface, based on four initial corner points. With "noise" from a random number generator (landscape stochastic factor) and a Hurst exponent for fractional Brownian motion, the additional grid points are calculated. We did not use the standard $\mathrm{C}$ random number generator, but an improved algorithm [67]. The three-dimensional surface is converted to a two-dimensional suitable-unsuitable map by the "valley flooding" method (in which "water" represents the suitable habitat). This method had slightly more realistic-looking landscapes than the "mountain-cut" method. We use a modified algorithm that allows for symmetrical and wrapped landscapes [58]. Symmetry prevents the entire suitable habitat to be in one corner, and wrapped boundaries give the landscape the appearance to be part of a larger landscape.

We implemented reflecting boundaries for bees foraging near the landscape border as follows. If the new coordinates for a move are calculated (with a change in $\mathrm{x}$, a change in $y$, and the new coordinate pair), we check whether one of the coordinates lies outside the grid. If so, we multiply the change in $x, y$, or both with -1 . This means that a line through the old coordinate pair, parallel to the border, functions as a mirror. We also prevented nesting at the border of the landscape, to prevent increased local competition by the reflecting boundaries. We scale this additional rule with body size: the minimal distance from the border where it is allowed to nest equals body length as given in meters (i.e., times 1,000 for body length in mm), and we rounded it to landscape grid cells. We have chosen this method after thorough experimentation with alternatives. The selected method has the best average bee performance with the least unwanted effects, but a little higher standard deviation (larger difference between individual bees) for bee performance. The field was always large enough to have most of the bees not nesting near the landscape boundary anyway.

\subsubsection{Patch Leaving Rules and Flower Encountering}

The probability of leaving a grid cell is based on the relative quality of the habitat grid cell compared with a previously visited one. This is calculated by dividing current habitat quality by the remembered habitat quality. Habitat cell quality is the fraction of successful flower visits to the total flower visits (based on a minimal number of flowers, fmem). If the upper patch threshold ( $\left.u \_p l t\right)$ is 1.0 and the current cell has at least the same quality as the last (value of 1.0 or higher), the probability of 
leaving is 0.0 . If the relative cell quality comes below a certain threshold $\left(l_{-} p l t\right)$, the probability of leaving is 1.0 and the bee flies up in search for a better location (behavior fly around). A third leaving threshold is determined stochastically (for each decision) from a uniform distribution between the upper and lower patch threshold (i.e., it differs per moment). If the relative cell quality is below this third threshold, the bee will search for resources in neighboring grid cells (behavior neighboring cell). For the upper patch-leaving threshold, we have chosen a value of 1.0, which means that a bee only stays for certain when the current habitat grid cell is at least as good as the previous one. The lower patch threshold should not be lower than 0.5 , because otherwise bees would stay in a grid cell with less than half of the quality of the previous grid cell.

For determining the success of a flower visit, we first calculated the proportion of full flowers in the habitat grid cell. We did not track the pollen volume of each flower in the landscape, but the pollen remaining per grid cell. When we divide this first over the pollen volume per flower and then over the number of flowers per grid cell, we have an estimate for the proportion of full flowers in that grid cell. Since we assume homogeneous vegetation, all habitat grid cells have the same amount of flowers based on flower density. For each landscape grid cell with foraging habitat, we track the amount of pollen left, as approximation for the number of full flowers. We use the proportion of full flowers as probability for encountering a full flower. If a full flower is encountered, the bee takes up pollen according to its uptake capacity, and the amount of pollen in that grid cell decreases by the same amount. The bee receives a time penalty for collecting the pollen. For both full and empty flower encounters, a bee receives a time penalty for flying to the flower (based on distance and velocity).

\subsubsection{Determination of the Maximum Distance Allowed to Fly on a Foraging Trip (Distance of Certain Return)}

We used the relatively well-studied homing distance to set a maximum foraging distance per foraging trip. First, we calculated the typical $(r 50)$ and far $(r 90)$ homing distance (distance beyond which $50 \%$ and $90 \%$ of the bees were not able to return at release, respectively) for a bee of a certain size (Table 10.3) based on a known allometric relationship [62]. We use a hyperbolic Michaelis-Menten function to describe a homing probability curve. We could solve the equation with two parameters ( $r 50$ and $r 90$ ) for a bee of a certain size. Since a Michaelis-Menten function normally goes through the origin and we preferred to have a range of $\mathrm{x}$ values (close to the nest) for which a bee would be able to return (minimal knowledge of the environment), we shifted the curve, based on the two known points ( $r 50$ and $r 90$ ) on this curve (Table 10.4, row B, calculation of shift). We did this by solving the altered equation for homing probability (Table 10.4, row B) where 50\% and 90\% homing probability share the same shift value, resulting in the equation for shift, which alters the saturation constant $K m$ accordingly (Table 10.4, row B). The return or homing probability can then be calculated as a function of distance from the nest (Table 10.4, row B).

The response homing probability can also be interpreted as the probability that an individual has reached the distance beyond which it has no knowledge of the environment (will not be able to return home to the nest). 
We know that bees fly exclusively within their homing range, which differs between individuals and within different directions. We decided to include this in the model as distance beyond which a bee is not allowed to fly and was calculated for each individual, on each foraging bout. We inversed the calculation (Table 10.4, row $\mathrm{C}$ ), giving a stochastically determined distance per foraging trip beyond which foraging is not allowed. This reproduces a realistic set of distances from the nest where the bee should maximally return, never close to the nest and with a similar shape as for real foraging data [68]. An asymmetrical S-curve would probably be a good alternative, but we could not fit it with two known points.

\subsubsection{Pattern-Oriented Modeling}

We used a pattern-oriented modeling (POM) approach [69,70] to parameterize the behavioral rules of the model. The visitation pattern (grid cells where bees left one or more visitation marks) showed that bees with area-restricted search and a limited memory easily fly back to old patches and grid cells and never cross the matrix (Figure 10.4b). We considered the behavior "too locally optimized." Foraging resources appear "in sight," when flying parallel to the vegetation, and such a grid cell is visited when it is not memorized (10 last visited grid cells are in memory). We added a parameter (ignorance) that lets the bee ignore decisions with a certain probability (details in Section 10.3.1). This probability assumes an innate preference of solitary bees to occasionally take the risk of crossing the matrix for finding

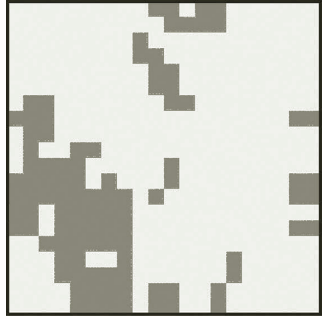

(a)

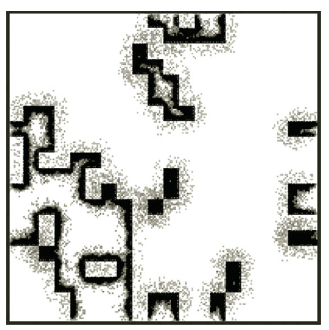

(b)

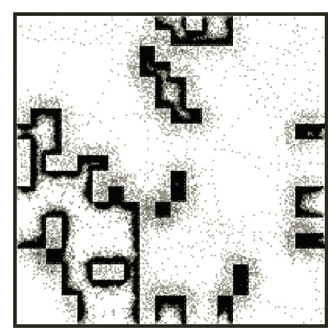

(c)

FIGURE 10.4 An example landscape with two visitation responses for bee communities with slightly different foraging behavior. (a) An example landscape with fragmented (meadow-like) fields. The darker shade of gray represents the foraging habitat in an unsuitable matrix. The smallest patch measures 0.25 ha (50 by $50 \mathrm{~m}$, landscape element size). In this example, around 1,400 individuals (large bees) nest in woody structures at the border of the vegetation. Nests are represented by 1,400 small white dots at edge structures (partly sharing the same grid cell and hard to represent at this spatial scale, see also Figure 10.7). (b) Visitation by a community of large bees, in the first 8,000 s of simulation. The darkest shades of gray represent the highest total visitation and white no visitation (excluding nest sites). There is only flight activity around the border where the bees nest, where they find sufficient foraging resources. The grayscale is optimized to visualize single "visitation marks" as well. (c) Visitation of a bee community similar as in (b) but with introduced ignorance. Single flight paths can be recognized and the bees cross occasionally the matrix and the interior of fields with foraging habitat. 
far resource patches with higher resource abundance instead of optimizing the short-term profit. We decided that a value of 0.1 (ignoring $10 \%$ of the optimal decisions) results in a more plausible foraging pattern (Figure 10.4c). Bees now sufficiently cross the matrix and search for better patches outside the local patch. They also visit more often the interior of a flower field.

\subsection{LITERATURE REVIEW}

This section concerns the ecology of solitary bees. We review the relevant literature that we used to develop the model and to select realistic parameter values. We aim to identify the complete biological range of the parameters and to identify the most common values. We also explain in more detail how we selected our foraging rules for the model with literature support. Finally, we explore the literature for the response variable of the model that we later use to validate the model.

\subsubsection{Natural Parameter Ranges, Extremes, and Common Values}

We discuss the parameters from Table 10.1 with a literature review. The results from this review, the biological range of each parameter, is included in Table 10.1.

\subsubsection{Body Length}

Body lengths of wild bees normally vary in most parts of the world between 4 and $28 \mathrm{~mm}$ [2]. In the model, we focused on 6,12 , and $24 \mathrm{~mm}$ body length for small, intermediate-sized, and large bees. We chose to model small bees of $6 \mathrm{~mm}$ because this covers a wide range of common bees from different genera: Ceratina, Chelostoma, Heriades and Hyleaus (wood and cavity nesting), Dufourea, and several bees from the genera Halictus and Lasioglossum (soil-nesting). Most bumblebees, which are wild bees but not solitary bees, range from 12 to $18 \mathrm{~mm}$ (10-25 for more extreme species). However, we chose a smaller group of solitary bees to represent the outer range of body sizes $(24 \mathrm{~mm})$. Wood-nesting bees from the genus Xylocopa measure 20-28 mm. Soil-nesting bees that are similarly large can be found in the genera Centris, Eulaema, Oxaea, Habropoda, and Xenoglossa. The main reason for including medium-sized bees (instead of only the two extremes) is that they are the best-studied group of solitary bees with the most reliable available data. Wellstudied, intermediate-sized bees (10-14 mm) are found in the genera Osmia and Megachile. Soil-nesting, intermediate-sized bees are found in the genera Andrena and Anthophora.

\subsubsection{Landscape Element Size}

Foraging and nesting resources for bees can probably be considered to have a fractal patch size distribution in the landscape. Even in large unsuitable regions, some smaller patches of several square meters and even single isolated flowers (down to a scale of square centimeters) can function as foraging habitats. Despite this, we used a coarse grain size $\left(50 \mathrm{~m}^{2}\right)$ for foraging resources for several reasons. Geographic information system (GIS)-based landscape maps often use a detail of $50 \mathrm{~m}^{2}$ and we also used this as grain size for foraging resources, and artificially generated 
landscapes with a grain size of $30 \mathrm{~m}$ were a good imitation of raster-based GIS maps in Hargis et al. [59]. Landscape elements with foraging resources are usually larger than those with nesting resources. A grain size (or element size) of $50 \mathrm{~m}$ as landscape detail (or somewhat smaller 0.2 ha blocks) has been used in several wild bee studies [44,45,71]. Furthermore, agriculturally dominated landscapes often have a patchy structure with large homogeneous blocks, rather than a fractal structure. The use of a grain size of $50 \mathrm{~m}$ in the landscape generator provides useful maps with foraging resources. Since nesting resources for bees are finer scaled (such as linear elements with scrubs or bare spots in the vegetation), we defined nesting resources with another method.

\subsubsection{Flower Density, Pollen per Flower, and Pollen Availability}

Flower density is a highly variable parameter. For solitary bees, the unit for visitation is the flower or flower head and not the plant. Flower densities are much higher than plant densities. For a homogeneous vegetation, flower density ranges from hundreds (Caltha palustris) to millions (Thalictrum aquilegiifolium, Ranunculaceae) per square meter [72]. High flower densities are often based on florets and not on flower heads, for example, from Centaurea species [73]. For nectar collection, these are probably realistic visiting units for bees. Active pollen collection by solitary bees is nevertheless a process on the flower(-head) level. The highest density we could find for single flower units (not composite flowers) was for Brassica napus (oilseed rape) and counted to more than $11,000 \mathrm{~m}^{-2}$ [74]. Lower densities can have any value. For clover, the flower(-head) density was counted at 50 inflorescences $/ \mathrm{m}^{2}$ [48] but Waddington reported a range of 50-250 [75]. Large flowers such as sunflowers are an exception and have a density below $10 \mathrm{~m}^{-2}$. Other low flower densities reported are often a result of downscaling flower densities from heterogeneous units on a larger (hectare size) scale.

The amount of pollen per flower varies considerably between species. Studies used different measurement units for pollen production and assessed them with various methods and only few compared different plant species with a wide range of pollen production. The first way to measure pollen production is by number of grains, which ranges from 1,100 to 150,000 [76]. A second method is by weighing the amount of pollen, which varies from 0.35 to $6.11 \mathrm{mg}$ for Ranunculaceae [72]. The third method is by calculating the pollen volume for each flower, which ranges from 0.05 to $21.7 \mathrm{~mm}^{3}$ [61]. For both pollen number and pollen weight, lower values can be found [77,78], but we did not find higher values. Calculating the pollen volume [61] is a relatively new approach without comparable studies, but the authors put special effort in covering a wide taxonomical range. We used pollen volume, because the most qualitative information of pollen transport by bees is measured in volume [61] and therefore in the same unit.

We use an additional parameter for pollen availability to regulate pollen removal. Many plants release pollen in portions in order to reduce the pollen that is taken in one visit and help the plant in optimizing pollination. There are many different syndromes for regulation of pollen release, which are widely distributed in the plant kingdom [79], and there are no general rules for gradual release and depletion of pollen. Our model flower does not mimic a certain flower type. We use a pollen 
availability of 0.3 per visit, a very general value. This maximum proportion of available pollen (initially present) at one moment is a plant trait and independent of bee size and allows for a minimum of at least three to four bee visits to the flower before being empty. Percentages of pollen removal at a first visit (bumblebees) vary from $20 \%$ to $80 \%[80,81]$. Depletion rates vary from almost all pollen from all plants after $2 \mathrm{~h}$ [82] to $60 \%$ of the pollen per flower after $3 \mathrm{~h}$ [83]. Some pollen will never be removed, about 1\%; see [83]. We also use decision thresholds in the model (explained later) that prevent bees to spend too much time on flowers that provide little (remaining) pollen.

We tried to balance these three different flower parameters in the model. The flower density and pollen production per flower regulate the amount of pollen per square meter. Field data (see, e.g., [72]) does not reveal a direct relationship between flower density and pollen production per flower, but still indicate a weak trade-off between flower number and pollen per flower (highest flower densities show a low pollen production per flower). We used 50 flowers $/ \mathrm{m}^{2}$ as flower density with a rather oligolectic bee in mind that only visits flowers of a certain species that has a more scattered distribution. In contrast, polylectic bees often visit many different flowers that have a high combined density.

There is, to our knowledge, no evidence that the size of the flower (and hence pollen production) is correlated with the size of the flower visitor; single plant species are visited by a diverse bee fauna, for example, [84,85].

Therefore, we model one flower type with a certain amount of pollen visited by all bees of all sizes. We decided to use relatively small flowers so that also the smallest bees have to visit several flowers before they have collected enough pollen. Therefore, we used a pollen volume of $0.5 \mathrm{~mm}^{3}$. This value is also close to the mean pollen volume of $0.6426 \mathrm{~mm}^{3}$ for one flower or flower head calculated from the data provided by Müller et al. [61]. In the analysis of the model, we explore the consequences of these parameter values, with more extreme values for both flower density and pollen per flower in simulation experiment 2 and the effect of moderate changes in pollen availability in simulation experiment 4 .

\subsubsection{Landscape Quality for Bees}

We used the parameter landscape quality for bees to set a basic bee density in the landscape that also varied with body size. A higher value implies lower bee densities and more available pollen per individual. Bee densities in the literature are often given in estimated number per hectare. Bee densities differ between natural habitats and crop areas. Density of Apoidea in natural grasslands was estimated at 256-1,500 individuals per ha and at $232-4,700 \mathrm{ha}^{-1}$ for alfalfa fields. Bee densities vary through the season with higher densities in spring [30]. For other habitats such as forests, woodlots, roadsides, and village parks, the estimates were lower, varying from 46 to 281 individuals per ha [86].

The parameter values for flower density and pollen per flower (Table 10.1), in combination with a value of 30 for landscape quality for bees, yielded between 204 and 87,209 bee individuals per $\mathrm{km}^{2}$. This span is caused by differences in body length and foraging habitat availability in the different landscapes. A low landscape quality value of 10 in combination with high resource conditions increased the number of individuals to 92,819 and 2,093,017 for large and small 
bees, respectively. Scaled to 1 ha (divided by 100), it becomes clear that these are still realistic densities. For seminatural habitats, a value of 30 yields more realistic densities (2-900) than a value of 10 (900-21,000) and is in balance with our moderate resource densities. Note that for extremely high values for flower density and pollen per flower (simulation experiment 2) extremely high individual numbers can occur in the model.

\subsubsection{Pollen per Brood Cell and Pollen Capacity per Bee}

The pollen volume that a bee requires for a brood cell clearly relates to body size [61] and was not further reviewed by us. The pollen volume transported by a bee per foraging trip is unknown, but it may scale in the same way with body size as the complete brood cell volume. Therefore, we assumed an average of 10 foraging trips per brood cell to define the capacity per bee. We assume a 1:1 sex ratio to cancel out effects of sexual dimorphism [87]. It is not clear whether the number of foraging trips per brood cell can be used as a constant, since sexual dimorphism and other factors cause variability. The number of collection trips per brood cell varies from 3 to 15 trips between species $[88,89]$. A range of other species, with a large span in body size, need 8-12 trips per brood cell [88,90,91], which suggests that 10 is an acceptable choice.

We made one other assumption with regard to the pollen capacity of bees and their behavior. In rare cases, the smaller bees find flowers with more pollen than they can transport. Bees deal with this in different ways. While one species completes the pollen load during a single visit, another species (from the same genus) visits several flowers regardless of pollen availability [91]. We argue that a bee needs to visit at least two flowers to be biologically meaningful to flowers. When the pollen available per visit from a flower exceeds the transport capacity of a bee (which means that the bee would be fully loaded), we set the pollen available to half of the normal availability. This rule was only invoked under extreme parameter combinations (e.g., very large flowers with abundant pollen in simulation experiment 2).

\subsubsection{Velocity}

In the literature, we found hymenopteran velocities from a wide taxonomic range, but almost none for solitary bees (Table 10.5). The listed values cover a wider range of body lengths than in solitary bees and were used to provide an allometric rule for high velocity and medium velocity.

\subsubsection{Flower Handling Time}

Handling times for exclusive pollen collection are rare in the literature, and most studies report handling times for mixed foraging tasks or for nectar handling alone. For the allometric scaling of pollen handling time with body length, we used three studies (Table 10.3). The first [102] gives values for five solitary bees and shows that handling time decreases with body length (Table 10.6). Solitary bees alone had a very narrow range of body sizes and we therefore included a honey bee and a bumblebee $[103,104]$. Data from another study with much longer handling times shows a similar negative relationship [4]. 


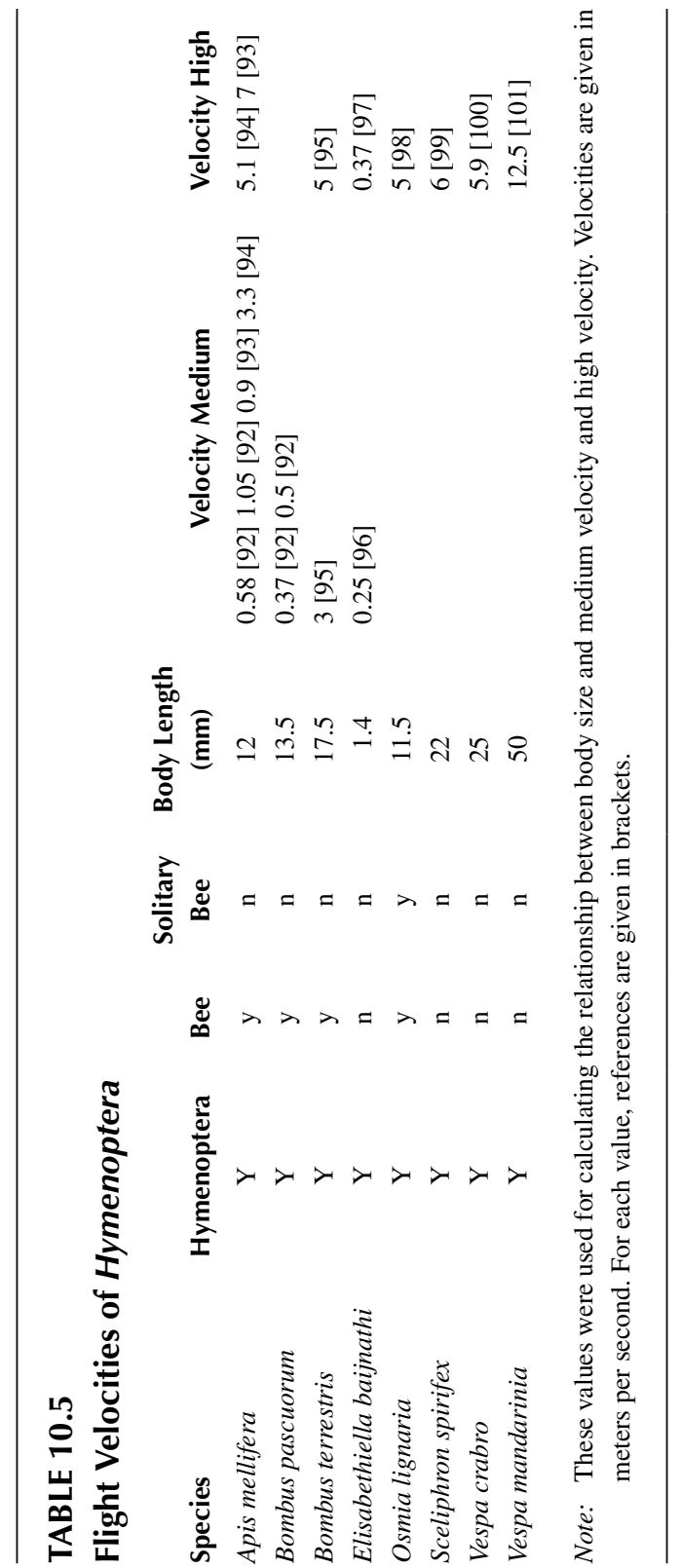


TABLE 10.6

Flower Handling Times for Pollen Collection Based on Three Studies

$\begin{array}{lccccc}\text { Species } & \text { Hymenoptera } & \text { Bee } & \begin{array}{c}\text { Solitary } \\ \text { Bee }\end{array} & \begin{array}{c}\text { Body Length } \\ (\mathbf{m m})\end{array} & \begin{array}{c}\text { Handling Time for } \\ \text { Pollen Collection (s) }\end{array} \\ \text { Hoplitis anthocopoides } & \mathrm{y} & \mathrm{y} & \mathrm{y} & 10.0 & 5.70[102] \\ \text { Megachile relativa } & \mathrm{y} & \mathrm{y} & \mathrm{y} & 10.0 & 10.40[102] \\ \text { Osmia coerulescens } & \mathrm{y} & \mathrm{y} & \mathrm{y} & 9.5 & 15.70[102] \\ \text { Hoplitis producta } & \mathrm{y} & \mathrm{y} & \mathrm{y} & 6.6 & 29.30[102] \\ \text { Ceratina calcarata } & \mathrm{y} & \mathrm{y} & \mathrm{y} & 6.2 & 31.70[102] \\ \text { Bombus terrestris } & \mathrm{y} & \mathrm{y} & \mathrm{n} & 26.0 & 4.60[103] \\ \text { Apis mellifera } & \mathrm{y} & \mathrm{y} & \mathrm{n} & 12.0 & 8.10[104] \\ & & & & & \end{array}$

\subsubsection{Perception Distance and Length of Flight Units}

There is no direct data on the perception distance of bees, but a body of literature exists on the visual abilities of bees showing that larger bees have better visual abilities. Eye size (facet or ommatidium diameter) of wild bees scales isometrically with thorax length [105]. Bees estimate their flight distance with the help of their velocity. Insects experience image motion (near objects appear to move faster than distant ones), mainly in a horizontal direction [106]. Honey bees estimate distance by holding a constant image velocity [107]. Because of the close link between velocity and perception, we defined the perception distance as the distance that can be flown in $10 \mathrm{~s}$ (view of $10 \mathrm{~s}$ forward). Since bees fly at several meters per second, the perception distance is several tens of meters. This may seem rather limited but wild bees generally fly 1-3 $\mathrm{m}$ above the ground [108] rather than higher up in the air with a wide view of the landscape.

We use flight units to model flight paths of bees, since flight paths are rather erratic than straight. Such flight paths suggest that a bee regularly evaluates (and adjusts) the flight direction. We defined a flight unit length as half of the perception distance and it was hence related to body size as well. In our implementation of movement (correlated random walk), we use slight deviations from this mean flight unit length in order to create natural-looking flight paths. We did not include any odometry in the model, because odometry only plays a minor role during foraging [109].

\subsubsection{Flower Memory, Habitat Cell Memory, and Ignorance}

Bees have different kinds of memory (e.g., [110]). We use flower memory and habitat cell memory in our model, since they play an important role in decision behavior. Bees need to probe and memorize several flowers to estimate patch quality. We defined patch quality as the ratio of full to empty flowers, which reflects the probability that the next flower is full. Data from solitary bees show that the decision to stay or leave (a patch) depends on the reward of at least one to three visited flowers [111]. We used a minimum of three flowers for flower memory. One flower (full or empty in the model) does not suffice for a patch quality estimate. Bees improve their 
estimates of patch quality by visiting more (than three) flowers. Since this kind of working memory lasts from seconds to minutes [112], we did not set a maximum of flowers that a bee can remember. Within minutes, the bee either found enough pollen or left the habitat grid cell. Apart from the fixed minimal number of flowers that must be probed (flower memory), we implemented further flower memory during foraging within a habitat grid cell as two numbers: the number of full and the number of empty flowers. On entering a new habitat grid cell, only the final ratio of full to empty flowers is remembered and acts as the expectation of resource quality to compare the new experience (new series of probing flowers) with.

Bees remember the most recently visited grid cells with flowers ( 5 by $5 \mathrm{~m}$ units within the larger-scale foraging habitat). It is not exactly known how bees remember this kind of information, but they have a spatial memory of their route and the landscape with landmarks [113]. We defined this memory (habitat cell memory) as 10 grid cell locations. We cleared this memory for each new foraging trip, leading to new exploration of flower habitat grid cells (including near the nest) and new foraging directions.

We introduced an "ignore parameter" to induce matrix crossing and "far resource exploration." Wild bees do not prefer to cross the matrix [46,114]. However, absence of matrix crossing is also unrealistic since some individuals do take that risk (about $10 \%$ ) [46]. Therefore, in the model, $10 \%$ of the local optimal decisions (going to a close habitat cell) are ignored. We decided to scale the parameter with habitat cell memory to reduce the number of independent parameters. They are inversely related (probability of 1 divided by the habitat cell memory), which means that for a bee with very little memory of its environment it is better to take more risks.

\subsubsection{Flight Path Tortuosity}

The turning angle distribution determines the tortuosity (erraticness) of the flight path. A higher value for flight path tortuosity results in more small turning angles and straighter flight paths. Turning angle distributions differ considerably between studies [115-119]. We use the correlated random walk with turning angles only to cross the matrix (area with no flowers); at the foraging habitat level, we use nearest neighbor selection rules (which indirectly lead to a very erratic flight path). For the matrix-crossing flight, we used a high value for flight path tortuosity (0.9), resulting in relative straight flight paths as known for areas with almost no foraging resources [118].

\subsubsection{Time at the Nest and Foraging Time}

The time that bees spent at their nest between foraging trips varies from 0.5 to $30 \mathrm{~min}$ [88]. A time below $5 \mathrm{~min}$ has been reported most often [91,120-122]. Time spent at the nest can be separated in a short time at the nest for pollen deposition (short stay) and longer time for egg laying and cell closure after a completed brood cell provision [121]. We do not know of an effect of body size (e.g., data collected in [88]) and nesting preference, but this may be a knowledge gap in the literature. We use time at the nest as pollen deposition time and assume that larger species remove pollen more efficiently (same amount of time for depositing more pollen) and use $0.5 \mathrm{~min}$ as value unbiased by other activities. Instant pollen deposition at the nest 
(time zero) would lead to unrealistically high levels of local competition, and a high value would lead to a very low competition between bees, because they spend most time at the nest.

We simulate one foraging day to measure the bee's foraging performance, assuming that days do not differ. This also keeps simulation time acceptable compared to multiple foraging days. Foraging time (flytime) is often described in the literature as species activity time lasting 8-12 h [120-124], but can be considered to be half of that value (4-6 h) for the peak activity time [120,121]. Foraging time (time of day used for foraging) also relates to body size and climate. Large species can generate more heat, which is needed to start earlier [125]. However, they also forage late in the day, but have low foraging activity at the middle of the day [126]. Hence, duration of peak activity may be considered equal between small and large species. Animals often restrict their food search to the optimal time as response to the periodic nature of temporal distributions of resources [127]. We therefore consider four to eight peak foraging hours as realistic values for foraging time. The combination of time at the nest and flytime determines how much pollen has been collected by the end of the day, and possible qualitative differences of different combinations are explored in simulation experiment 1 (Section 10.4).

\subsubsection{Data Support for Foraging Rules}

\subsubsection{Five Behavioral Modules}

Resource competition in time with time penalties for different tasks is an important concept for modeling foraging behavior of wild bees. Bumblebees spend their time performing different behaviors: they travel between nest and foraging patches, fly between flowers within a patch, handle flowers and remove nectar and pollen, and search for other rewarding patches [36]. For solitary bees, these tasks are the same. We modified these tasks to five different behavioral modules in the model:

1. Forage flowers (fly to flowers, forage flowers within a landscape grid cell, fly between flowers, handle flowers, and remove pollen)

2. Neighboring cell (fly to a suitable neighboring landscape grid cell)

3. Fly around (fly around and look for unknown foraging areas)

4. Fly back (fly back to nest)

5. Nest reached (deposit collected pollen)

The finding that some bees perform an exclusively nectar-feeding trip at the end of the day [121] was not included.

There are several indications that bees first deplete flowers in the closest patches around the nest. Solitary bees deplete all flowers under high bee densities [91] and some individuals keep small foraging areas [128]. Bumblebees forage differently compared to solitary bees by following traplines (foraging paths of considerable length that guide farther and farther away from the nest), but solitary bees forage more primitively within a few hundred meters of their nest [55]. Therefore, 
after behavioral module 5 (nest reached), bees start foraging again from the nest location. Pollen may also still be available, since the flowers did release only a proportion of their pollen (pollen availability) in one time. The higher expected patch quality (memorized from farther away at the preceding foraging trip) makes that the bee flies beyond the habitat cells near the nest with low resource levels.

\subsubsection{Use of Memory}

According to the current knowledge, five memory types can be distinguished for (eusocial) bees [110]:

1. Memory of link between olfactory stimulus and reward, which lasts only seconds (flower constancy choice)

2. Short-term memory of, for example, the last visited patches, which lasts up to several minutes

3. Mid-term memory of the last location of rewarding flowers when returning to nest, memory of sequential landmarks and time of day

4. Long-term memory of flower cues

5. Long-term memory of nest location (nest recognition cues)

We represent these levels of memorization in our model as follows:

1. Bumblebees use this memory for maintaining flower constancy, but the solitary bees in our model forage on one kind of flower. Nevertheless, the model bees memorize the numbers of empty and full flowers that they have encountered and remember the current patch quality. The minimal number of flowers needed to estimate a ratio between them is defined in flower memory.

2. The bees in our model remember the last visited habitat grid cells. The size of this memory (number of memorized locations) is defined in habitat cell memory.

3. Honey bees return to rewarding patches [110], but we assumed that solitary bees do not for several reasons. We are not aware of any study showing that solitary bees directly return to the previous rewarding patch; it is even doubted for some honey bee subspecies [129]. Bees that have low associative learning capabilities, behave more like individuals, and fly shorter distances from the nest are likely to visit different locations on different bouts [129]. Instead, we assumed that the bees remember the quality of the last visited habitat grid cell (ratio of full and empty flowers encountered) for comparison with a newer location. We also indirectly assumed a memory of landmarks, resulting in a nonstraight flight path back to the nest (directed correlated walk).

4. The solitary bees in our model forage on one kind of flower. Hence, recognition of the right flower (and flower cues) is assumed, not modeled.

5. The most basic memory of the bees in our model was their nest location to which they always return. 


\subsubsection{Within-Patch (Grid Cell) Foraging Behavior (Behavior 1: Forage Flowers)}

We reduced the biological detail within a habitat grid cell and made very simplified assumptions about foraging behavior. Remember that we do not use optimized foraging behavior (shown for nectar-foraging bumblebees) for the pollen-collecting solitary bees in the model. Further, we were interested in motivations of bees for moving between grid cells (landscape level), not in detailed movement within a grid cell. We implemented a "visit nearest flower" rule and resource evaluation rules (determining flower and patch quality). We considered the following facts for our implementation:

- Pollen-collecting solitary bees do not use scent marks as much as nectarforaging bumblebees do [130]. Flowers normally have abundant pollen (in contrast to nectar), and marking flowers is less profitable and too costly. Pollen is also mostly easily accessible than nectar. In the model, we do not use any kind of marking.

- Solitary bees are able to assess nectar reward by scent [131], but pollen recognition by scent has not been shown so far. We do not use a perception rule on this scale. Our model bee flies to a flower and receives a small time penalty for assessing pollen availability.

- Flight distance of bees flying between flowers is related to plant density [55]. We modeled the distance to the next flower as the mean distance between flowers, based on flower density.

- When bees forage on flowers, they use color contrast of multiple receptor types instead of the green contrast receptor type alone [132-134]. In order to locate a visible flower in the third dimension, bees need to adapt their velocity [106] and trade-off speed for accuracy [135]. We used therefore a lower velocity for within-patch (within-cell and between-cell) movements.

\subsubsection{Patch Selection (Behavior 2: Neighboring Cell)}

Honey bees cross vegetation structures very easily, but solitary bees were found to follow continuous vegetation structures [124]. We therefore implemented a module where only neighboring habitat cells are visited. The currently occupied cell is excluded from choice possibilities as well as recently visited habitat cells and nonforaging habitat cells. From the remaining cells, one is chosen randomly. This leads to a more or less random movement between habitat cells and a uniform distribution of turning angles with a larger-scale tendency to fly away from the nest. This movement behavior is not in contradiction with turning angle distributions found for bumblebees in rewarding flower patches $[118,136]$.

\subsubsection{Nest Clumping for Soil-Nesting Bees}

For a more realistic distribution of nests for soil-nesting bees, we distributed them somewhat clumped rather than uniformly. Soil-nesting bees prefer moderate [91] to very dense aggregations $[137,138]$. Not all locations within the vegetation are suitable to nest, and clumped nest sites are also better encounter sites for mating [55]. We used moderate clumping in our model (and did not further analyze this), since we were interested in the 
potential difference between soil- and wood-nesting bees and not in the effect of nest clumping (it does not change the contrast of the two nesting preferences per se).

\subsubsection{Exploration of Field Data for Response Variables}

We discuss here response variables of the simulation model: number of brood cells, distance flown (mean and far distance from the nest), trip duration, and number of flowers visited (per day and per trip). We discuss values for small, midsize, and large bees separately to get an indication of the range of values within each group.

\subsubsection{Number of Brood Cells}

The number of brood cells that bees build in 1 day spans a large range between species and within species. Bees from the genus Andrena (covering probably the whole range of small to large bees) build 0.4-2 brood cells a day [88]. The small bee Calliopsis persimilis $(<8 \mathrm{~mm})$ even builds up to 6 a day [121]. Intermediatesized bees are relatively well studied. Osmia cornuta builds half a cell a day [139], Andrena humilis builds 1.37 brood cells per day [88], Osmia lignaria can build 2 cells a day [44], and Diadasia rinconis builds 2-3 cells a day [91]. However, Osmia bicornis may build up to 7.1 cells a day in optimal conditions [122]. A large bee, Creightonella frontalis, was found to build 1 cell a day [140] and another one, Dieunomia triangulifera, 0.2-3 brood cells per day [141]. This suggests in summary that small bees are able to build more brood cells in 1 day than large bees.

\subsubsection{Foraging Trip Duration}

Trip duration of different solitary bees (body length 7-12 $\mathrm{mm}$ ) lasts 6-28 min and is positively correlated with body length [142]. Another review found that trip duration for different species varies from 3 to 170 min [88]. Small bees show a particularly large range of trip durations. Perdita opuntiae needs about 4 min per trip, P. texana 6 min, and other Perdita species 15-30 min [91]. Calliopsis persimilis has foraging trips of $8 \mathrm{~min}$ [121], Chelostoma florisomne has pollen collection trips of about 20 min [143], and trips for Lasioglossum figueresi last 7-46 min [144]. For intermediatesized bees, the range is less extreme. Osmia cornuta for pollen collection in apple orchards needs 4.7 min per trip in one experiment [120] and in another experiment 5-6 min [122] and in almond orchards around $12 \mathrm{~min}$ [87]. For $O$. cornuta and $O$. rufa, it is known that they have series of longer (8-17 $\mathrm{min}$ ) and shorter trips (1-4 min) [122]. For Andrena humilis foraging trips range from 2 to $35 \mathrm{~min}$ [88]. Large solitary bees have longer foraging trip durations. Anthophora acervorum needs 14 min per trip in apple orchards [120], Xylocopa pubescens and X. sulcatipes need on average 20-30 min per trip (which was equal for pollen and nectar trips) but could last up to $78 \mathrm{~min}$ [145], Creightonella frontalis takes about 17 min for pollen collection [140], and for Dieunomia triangulifera, the trip duration varies from 20 to $190 \mathrm{~min}$ [141].

\subsubsection{Flowers Visited and Flowers Visited per Trip}

Small bees visit fewer flowers than large bees [85], and they visit only a few flowers per foraging trip [146]. It was estimated that Osmia cornuta (an intermediatesized bee) visits about 50 flowers per trip and about 4,500-5,600 flowers a day. 
Others estimate 60-90 flower visits per trip for $O$. cornuta [87], which would mean about 10,000 flowers a day. Large bees visit most flowers. Anthophora acervorum is estimated to visit about 250 flowers per trip and about 8,800 flowers a day [120], Creightonella frontalis 29 (full) flowers per trip and about 180-300 (full) flowers a day [140], Xylocopa pubescens and X. sulcatipes 15-20 (full range 4-65) flowers per trip [145], and bumblebees 20-150 flowers per trip [146].

\subsubsection{Mean Distance from Nest and Realized Foraging Range}

Small bees forage near the nest. Perdita texana has most foraging activity within $20 \mathrm{~m}$ from the nest with the longer flights around $40 \mathrm{~m}$ from the nest [91]. Also, Calabuig found that most solitary bees (among many small ones) forage mainly within the first $27 \mathrm{~m}$ [63]. An experiment with fluorescent dye showed that most pollen was transferred over short $(<15 \mathrm{~m})$ distances [147]. The mean activity distance for an intermediate-sized bee, Andrena hattorfiana, was 46-76 m (two sites), and the maximum distance was $83-130 \mathrm{~m}$. Rare long dispersal movements (which can be assumed to come close to the homing distance) were up to $900 \mathrm{~m}$ [46]. In resourcerich environments, Osmia cornuta forages near the nest within 100-200 m [148]. Bumblebees (large bees) are in contrast to small solitary bees and are also frequently flying farther (100-200 m) from the edge [63]. For other bumblebees, it was found that $40 \%$ foraged within $100 \mathrm{~m}$ around the nest and $62.5 \%$ within $200 \mathrm{~m}$ [149]. The mean maximum foraging distance per colony varied from 460 to $710 \mathrm{~m}$, and all bumblebees foraged within $800 \mathrm{~m}$. The mean foraging distance varied from 87 to 447 [149]. When food is abundant close to the nest, as it is, for example, in a clover field, bumblebees have their main foraging activity within $18 \mathrm{~m}$ from the nest [150].

\subsection{EXAMPLES OF SIMULATION EXPERIMENTS}

We performed four simulation experiments in order to gain a basic understanding of the model and to understand the influence of the different parameters. These experiments include the basic calibration and validation of the model as well as exploration of global perturbations within the parameter space and quantifying local sensitivity of the parameter values. These simulation experiments can be considered as examples of how one can analyze a multiparameter model such as our individual-based simulation model. At the same time, these simulation experiments can yield a basic understanding of the model system. In our case, they give insights into how solitary bees experience the landscape. All parameters are listed in Table 10.7, and for each simulation experiment the used values are given.

Statistical analyses on simulated outputs were performed with R [151]. Statistical analysis of simulation results is relatively unusual since the majority of the model is deterministic, which means that all parameters have a significant influence. However, the model has many rules that interact so that we could not predict a priori which of the parameters would have the most effect on the response variables, and statistical tools can help in ranking the impact of different parameters. We look at different response variables: number of brood cells, number of flower visits, mean distance from the nest, and foraging habitat visitation. In simulation experiment 1 , we additionally look at the mean trip duration and the maximum foraging distance. 


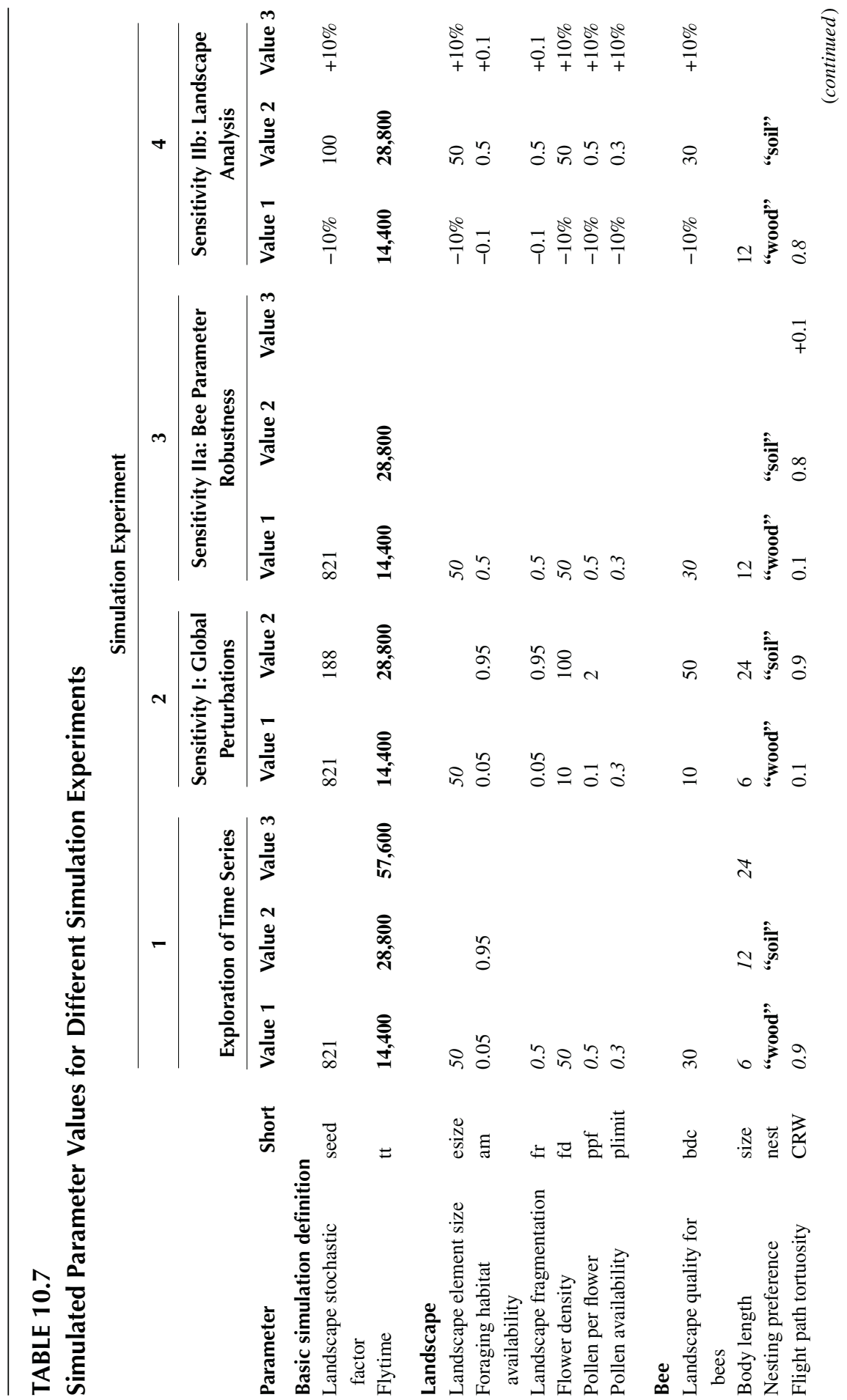




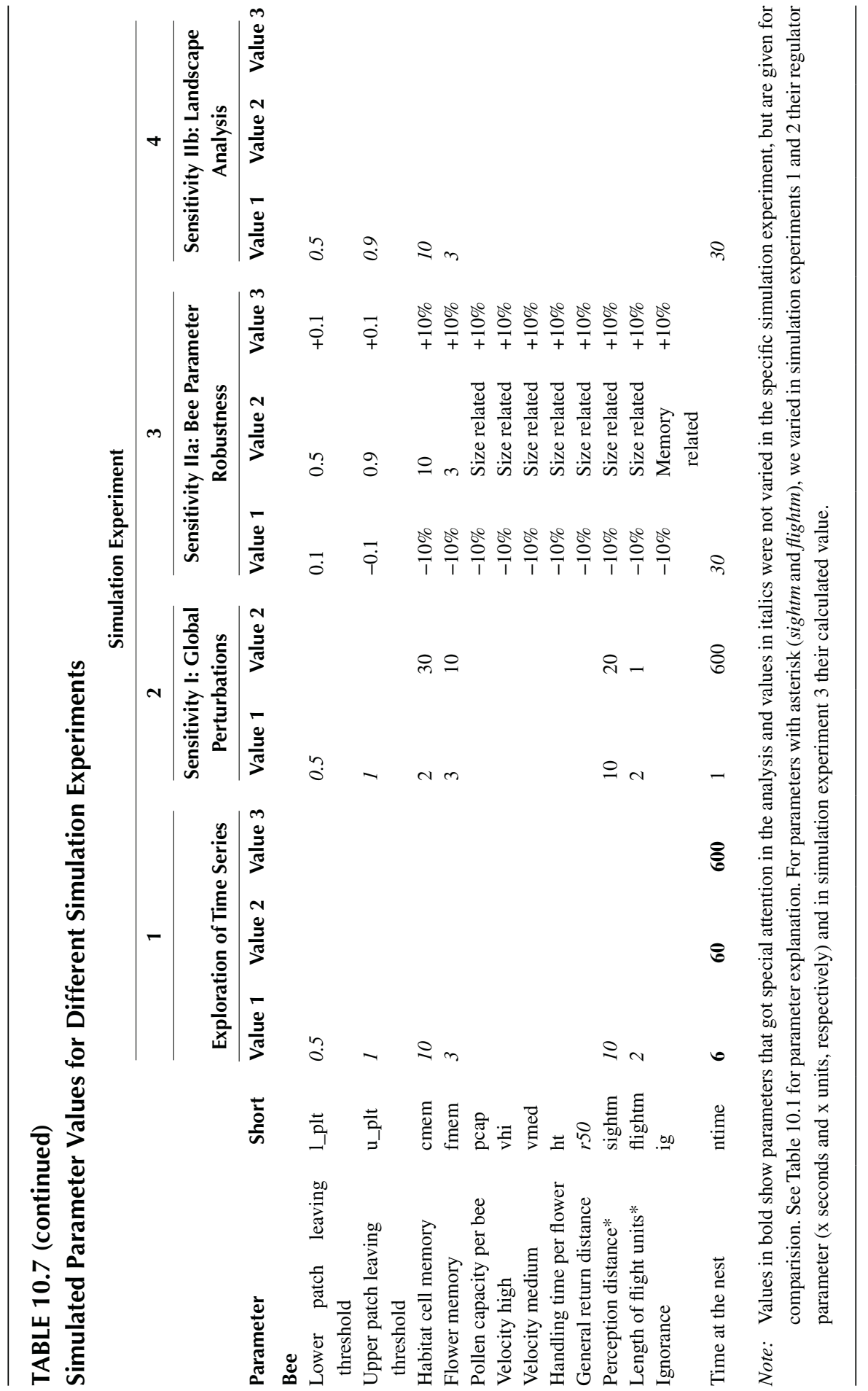




\subsubsection{Foraging for Pollen: Competition Processes in Time}

In this first simulation, we performed a systematic exploration of the model. We assessed how the model behaves over time, and how well output parameters overlap with literature data. There are two parameters in the model that determine the global time budget for bees: foraging time (flytime) and the time spent at the nest for pollen deposition (time at the nest). Since field data cover a wide range of values (Section 10.3.1), we investigated whether different combinations have only quantitative or also qualitative effects. We simulated three time-budget scenarios: a foraging day of $4 \mathrm{~h}$ with $6 \mathrm{~s}$ at the nest after each foraging bout, a foraging day of $8 \mathrm{~h}$ with $60 \mathrm{~s}$ at the nest, and a foraging day of $16 \mathrm{~h}$ with $600 \mathrm{~s}$ at the nest. We used unequal intervals for time at the nest for two reasons. First, it suits the biological values best (Section 10.3.1) and second, we expect that with longer foraging days the relative effect of time at the nest decreases (due to longer foraging trips and farther foraging distances). We explored a system that is unsaturated with bees (where there is more pollen than what bees collect in one day, defined by $b d c$ ). We varied body length $(6,12,24 \mathrm{~mm})$ and explored the results for the three bee sizes separately. To reduce complexity we omitted bee sizes from the description of the results when they did not provide additional insights. We therefore describe time series for brood cells and flower visits for small and for large bees, and the other time series for large bees only. We simulated four combinations of nesting preference (two types) and foraging habitat availability (0.05 and 0.95). This gives 12 time series per bee size (Table 10.7). Within each time-budget scenario, we ranked the four time series (their values at the end of the simulated time) to trace qualitative differences.

\subsubsection{Number of Brood Cells}

Within the foraging time (flytime), the number of completed brood cells increased. The pattern for different time-budget scenarios was similar between small bees (Figure 10.5a) and large bees (Figure 10.5b) as well as for intermediate-sized bees (not displayed). The flytime determined the absolute number of brood cells that could be built in 1 day, and the time at the nest determined how fast (change in slope) a certain number of brood cells is built. The relative distance between different values for the time at the nest (6-60-600) is reflected in the relative distance between the curves. These two time-related parameters did affect the time budgets and remaining time for pollen collection as expected. The ranking of the performance (brood cells) of the bee types (ranking of the four response curves) was equal for all three time-budget scenarios.

The number of brood cells increased linearly for soil-nesting bees in all cases, which means that they were not resource limited by competition. Wood-nesting bees performed badly when they faced a high foraging habitat availability, which may seem counterintuitive. The increase in brood cells additionally leveled off for them, as well as for wood-nesting bees in landscapes with low foraging habitat (but weakly). These striking differences may be related to the different distribution of nests between soil- and wood-nesting bees, which induced other time constraints (Figure 10.7). Small bees were able to build more brood cells than large bees, and no bee was able to collect pollen for 30 brood cells (as defined in $b d c$ ). 

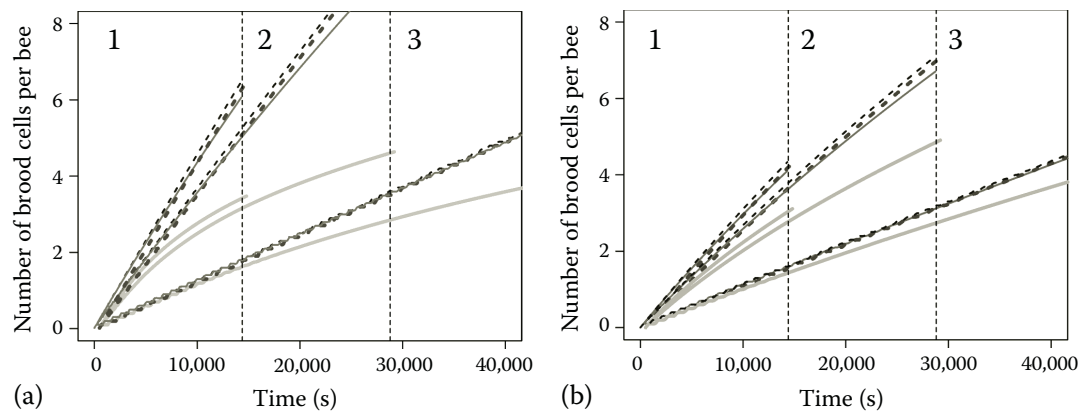

$$
\begin{aligned}
& \text { - Soil nesting, low amount of foraging habitat } \\
& \text { - Soil nesting, high amount of foraging habitat } \\
& \text { - Wood nesting, low amount of foraging habitat } \\
& \text { Wood nesting, high amount of foraging habitat } \\
& 1 \text { Set } 1: 4 \mathrm{~h} \text { foraging } 6 \mathrm{~s} \text { at nest } \\
& 2 \text { Set } 2: 8 \mathrm{~h} \text { foraging } 60 \mathrm{~s} \text { at nest } \\
& 3 \text { Set } 3: 16 \mathrm{~h} \text { foraging } 600 \mathrm{~s} \text { at nest }
\end{aligned}
$$
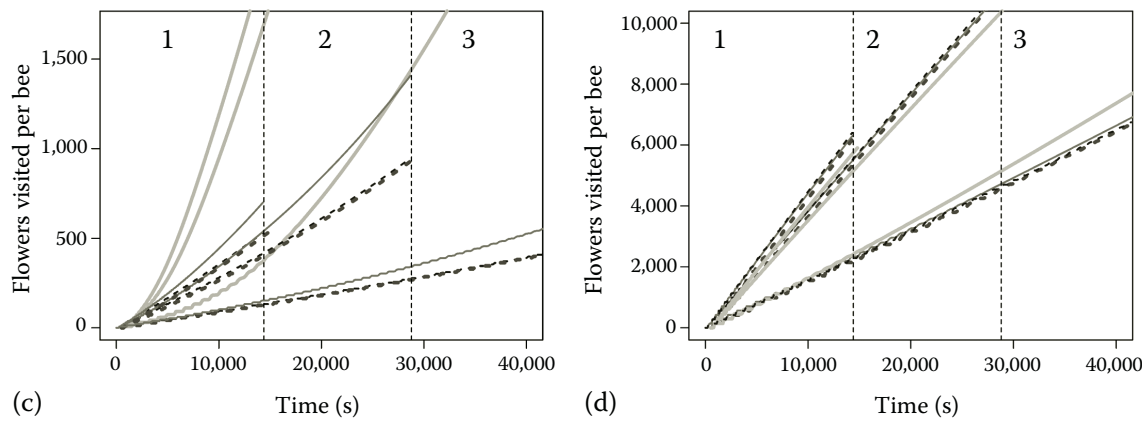

FIGURE 10.5 Development of different response variables during simulation time. Each graph contains 12 time series, of which 4 have the simulation time (flytime) ending at 14,400 s (first dashed vertical line), another 4 at 28,800 (second dashed vertical line), and the last 4 outside the graph on the right (at 57,600). Each subset of four represents a different scenario according to nesting preference and foraging habitat availability. The curves of each of the four scenarios are directly comparable with the curves in the other two time-budget scenarios (set 1-3). Note that we cut off the top of the $y$-axis to visualize the lower values so that some of the curves reach the vertical dashed line (simulation end) outside the plot. We shifted the lines for "high foraging habitat availability" with $500 \mathrm{~s}$ to make them distinguishable from other lines. (a) Brood cells built by small bees, (b) brood cells built by large bees, (c) flowers visited by small bees, and (d) flowers visited by large bees.

\subsubsection{Number of Flower Visits}

The number of flowers visited per bee (full and empty flowers) increased exponentially for all bees (Figure 10.5c and d). Hence, bees probed more flowers per time unit hinting to more empty flowers later in the day. Large bees (Figure 10.5d) visited many more flowers than small bees (Figure 10.5c). For most bees, the increase in flower visits was almost linear (Figure 10.5c and d), while for some small bees there was a strong exponential increase (Figure 10.5c). 
We suspect that large bees and soil-nesting small bees (Figure 10.5c and d) had better access to full flowers than wood-nesting small bees (Figure 10.5c). Woodnesting small bees visited more flowers per time unit later in the day and they built fewer additional brood cells per time unit (Figure 10.5a). Hence, they faced more empty flowers, leading to a higher flower visitation rate. Their nest position at the border of the habitat and their higher numbers and lower flight capability may have limited their access to less depleted areas.

The ranking of the response for the different bee types was the same again under the three time-budget scenarios, except for large bees with ntime 600. At this point, we cannot give a sufficient explanation for that. Time budgets for flower visits were apparently not the same time constraints that determined the pattern for the number of brood cells (Figure 10.5a and b).

\subsubsection{Normal Foraging Activity and Far Foraging Activity}

Far foraging distances (Figure 10.6b) were in most cases about twice as large as mean foraging distances (Figure 10.6a). Foraging experience (distance) increased almost linearly for soil-nesting bees and did not reach high values indicating that they found foraging resources close to the nest. Wood-nesting bees flew farther than soil-nesting bees, especially when they were in a landscape with high foraging habitat availability (Figure 10.6a and b). Wood-nesting bees were forced to nest in edge structures, while soil-nesting bees were more or less evenly distributed over the foraging habitat. Since in landscapes with high foraging habitat availability there were more bees and less edge (Figure 10.7), depletion around the nest was more likely for wood-nesting bees and resulted in farther foraging from the nest.

The expansion rate of bees decreased with time (Figure 10.5a and b). We implemented a foraging rule that prohibited flying too far from the nest (Section 10.2.7) and that could have caused this. We used parameters $r 50$ (typical homing distance) and $r 90$ (the far homing distance) to rule out exceeding these distances for $50 \%$ and $90 \%$ of the flight trips, respectively. The value for large bees was $6,760 \mathrm{~m}$ for $r 50$ and $16,017 \mathrm{~m}$ for $r 90$. Large bees never reached these distances (Figure 10.6a and b), and this hard-coded foraging rule cannot have been the cause for the decrease in expansion rate. All patterns in Figure 10.6a and b are in agreement with Figure 10.5a and $\mathrm{b}$ and may indicate that longer flights directly result in fewer brood cells.

There were no qualitative differences (same ranking) between the three timebudget scenarios. Far foraging distances (Figure 10.6b) were based on rarer expansion events, and the increase was therefore less smooth and more stochastic.

\subsubsection{Expansion over the Foraging Habitat}

The model tracked at the landscape level how much of the foraging habitat was visited by the bee community (Figure 10.6c, large bees). Soil-nesting bees covered within 3,000 s the complete vegetation (100\%) in landscapes with low foraging habitat availability and $90 \%$ of the vegetation in landscapes with high foraging habitat availability. This means that they had good access to all foraging resources without depleting it within a foraging day (brood cells increase with the same rate throughout the day, Figure 10.5a). Wood-nesting bees that nested at the border of the foraging 


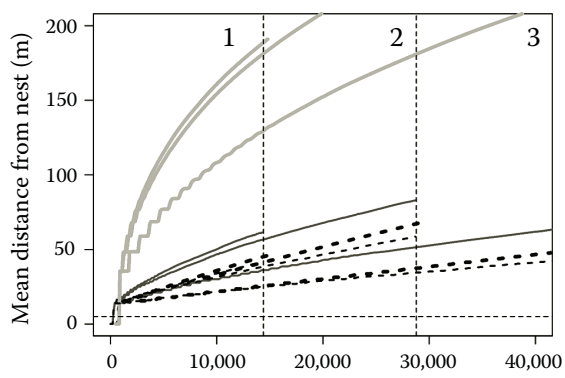

(a)

Time (s)

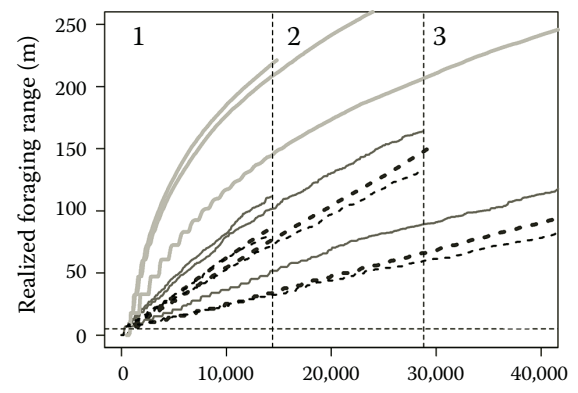

(b)

Time (s)

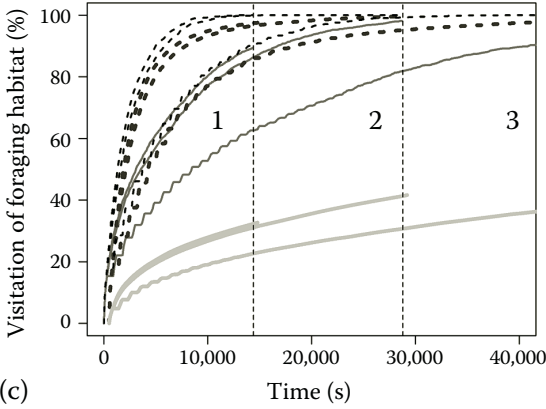

(c)

FIGURE 10.6 Progress during simulation time of expansion-related parameters for large bees. Each graph contains 12 time series, as in Figure 10.5 (see for details). (a) Mean distance from the nest, (b) maximum realized foraging range (averaged over the bee community), (c) visitation of foraging habitat, and (d) mean trip duration for large bees. Plots (a) and (b) start actually at the minimum distance of $5 \mathrm{~m}$ (size of one grid cell) indicated with a dashed line. The mean foraging distance seems (but is not) higher than the realized foraging range in the first few minutes, which is attributable to slightly different assessment methods in the model. Plot (d) starts at the "emerged" minimal trip duration.

habitat did not cover the whole foraging habitat. In a landscape with low foraging habitat availability, the bee community reached $85 \%$ within a foraging day, but in a landscape with high foraging habitat availability, the bees never covered more than $40 \%$ of the foraging habitat in these simulations. The ranking remained the same for all three time-budget scenarios.

\subsubsection{Trip Duration}

The mean trip duration increased during the day for all situations (Figure 10.6d), but was generally low (below $10 \mathrm{~min}$ ). Soil-nesting bees had the shortest trips and woodnesting bees had the longest trips, especially those in landscapes with a high foraging habitat availability, in agreement with longer foraging distances (Figure 10.6a). The ranking of the four responses did not change for the three time-budget scenarios. 


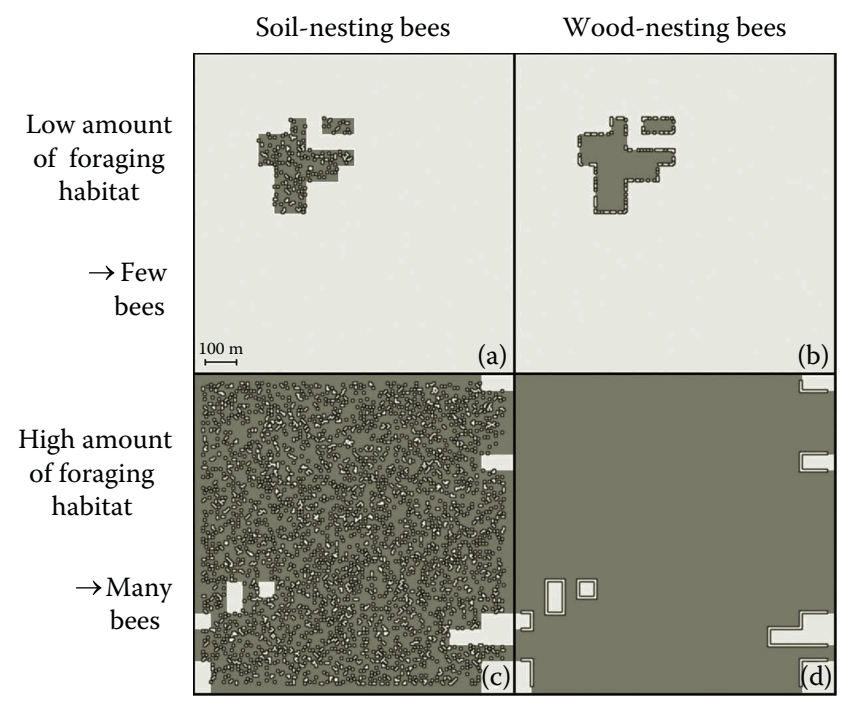

FIGURE 10.7 Four simulation examples after the initialization phase. The panels represent the four combinations of nesting preference and foraging habitat availability from simulation experiment 1 . These landscape realizations have a certain amount of foraging habitat (darker gray areas in a matrix without foraging resources), an intermediate fragmentation level, and a population of large bees. A bee's nest is represented as a white dot with a dark border. High nest densities appear as merged circles (white stripes with a dark border). (a) Population of soil-nesting bees with a low foraging habitat availability. (b) Population of wood-nesting bees in a landscape with a low foraging habitat availability. (c) Population of soil-nesting bees in a landscape with a high foraging habitat availability. (d) Population of wood-nesting bees in a landscape with a high foraging habitat availability.

\subsubsection{Time Budget Scenarios}

The three different time-budget scenarios for flytime and time at the nest had only quantitative effects (with the number of flowers visited by large bees as the only exception) and did not change the relative difference between the different bee types in different landscapes. Hence, we consider it acceptable to use a single time-budget scenario for systematic investigation of other parameters. Further, we found clear differences for bees of different size and for soil-nesting and wood-nesting bees, which are worth exploring in detail.

\subsubsection{How Well Does the Model Represent Foraging Solitary Bees in Real Systems?}

We used the results (mean values at the end of a foraging day, Figures 10.5 and 10.6) from this first simulation experiment (with uncalibrated, but realistic parameter input) to compare with data from real systems. We collected data from the literature with a focus on pollen-collecting solitary bees for several response variables: brood cells per day, foraging trip duration, flowers visited (per day and per trip), mean foraging distance from the nest, and far foraging distances within a day (Section 10.3.3). We present here an overview of the value ranges (grouped for small, midsize, and 
large bees as solution for the sparsely available data) and compare them with the ranges from the simulations (Table 10.8).

The model reproduced values quite similar to those of natural systems with overlapping ranges in the majority of the cases (Table 10.8). For all responses, the direction of change between small and large bees was correct, and also the intervals between the three bee sizes were similar between modeled values and real values. However, there were also differences. The modeled bees built more brood cells per day than in natural systems, had shorter foraging trips, and flew shorter distances. These responses were related to each other in the time series (Section 10.4.4.1). The number of flower visits in the model overlapped well with literature values for intermediate-sized bees, but not so well for small and large bees. The literature data for flower visits was sparse and lacked specification of whether or not unsuccessful flower visits were included (they were included in the model), which could explain the underestimation.

The modeled response variables yielded realistic values for small, intermediatesized, and large bees, and the modeled ranges generally overlapped well with real systems. The model bees were however more efficient than in most natural systems. A (too) high number of brood cells may have arisen from less realistic model assumptions such as the exclusion of nectar-foraging trips. Also collecting mud and other nest material can take considerable time [140] that is not available for collecting pollen. Some solitary bees only build one cell per day regardless of pollen availability and remaining time [91] and are rather egg-limited [152]. Other assumptions were that bees collect pollen for 1 brood cell within 10 foraging trips (used to define the loading capacity per trip), and bees always had a full load when they return (except when flying too far), which is often not the case [153]. In the model, bees always chose the most efficient place to nest: near foraging resources, either in the soil between the vegetation or at the border of the field. In agricultural landscapes, where much of the data originates from, distances between nest and foraging resources may be larger. Hence, it makes sense that the data shows less efficient bee performance as well.

We think that the model yields realistic output and that the overlap with literature data is satisfactory, also considering the fact that we used detailed, literature-based input values without fitting any parameter. This simulation experiment has also shown that the model shows realistic patterns in time. For example, an increasing foraging trip duration during the day is a well-known time effect for pollen-foraging bees that face local pollen depletion $[88,140,141]$.

\subsubsection{What Do Extreme Parameter Values Imply for Solitary Bees? A Global Sensitivity Analysis}

The goal of this second simulation experiment is to quantify parameter effects within their estimated biological range (Section 10.3.1) and to identify the most important ones. We analyzed the relative effect on brood cells for 15 parameters (flower density [fd], landscape quality for bees [bdc], pollen per flower [ppf], scaling parameter for perception distance [sightm], scaling parameter for length of flight units [flightm], flight path tortuosity [CRW], flower memory [fmem], habitat cell memory [cmem], time at the nest [ntime], and landscape stochastic factor [seed] 


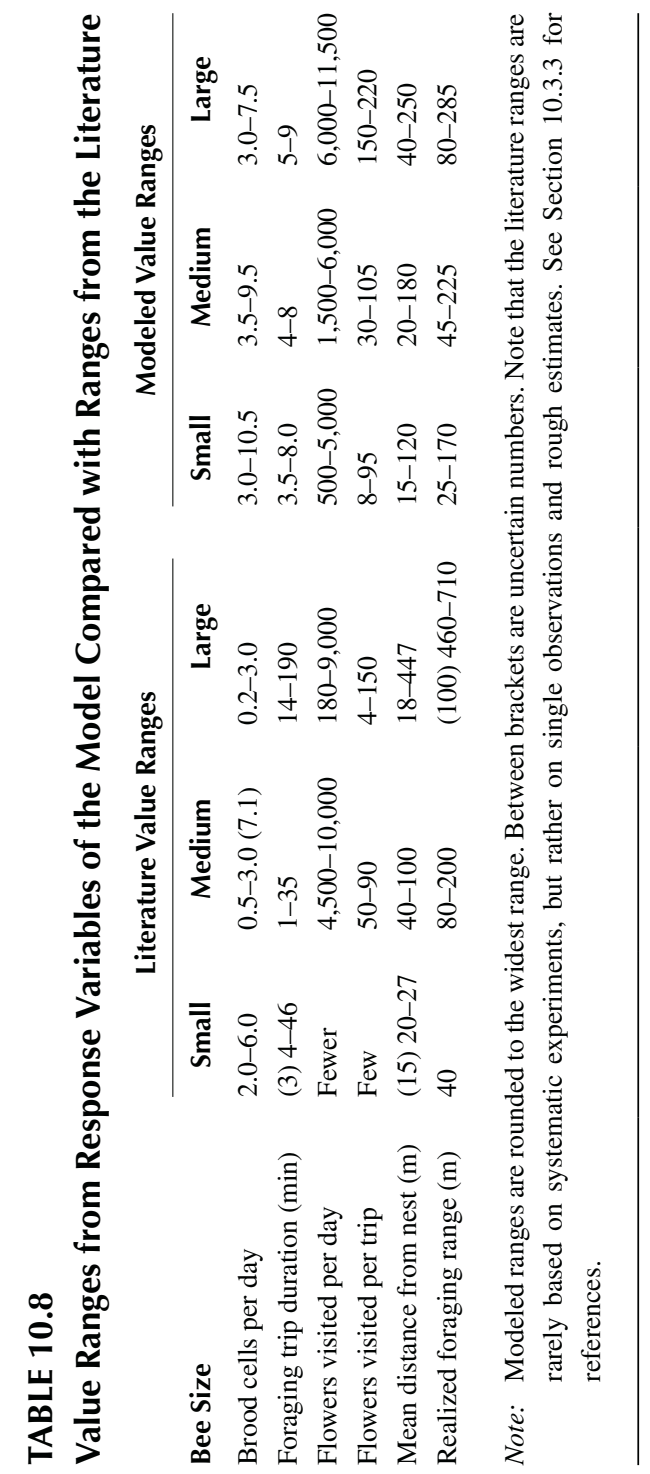


and included the focal parameters body length [size], nesting preference [nest], foraging habitat availability [am], and fragmentation [fr]). We used two values for each parameter representing the biological range (Section 10.3.1). The values for flower density, pollen per flower, and landscape quality for bees were restricted by simulation resources (parameter combinations that resulted in several millions of bees required too long running times) and not simulated for the most extreme values, but the chosen values cover an acceptable extent of biological range (Table 10.7 and Section 10.3.1). We generated a set of parameters for each possible combination $\left(2^{14}\right.$ combinations) and selected 2,000 of these sets randomly for simulation. We repeated the analysis for a longer foraging time (flytime). We present here the most important parameter effects and parameter interactions based on linear models for the different response variables.

\subsubsection{Brood Cells}

The number of brood cells was most affected by the pollen per flower, time at the nest, and landscape quality for bees. More total pollen (pollen per flower) and more pollen available per bee (landscape quality for bees) resulted in more brood cells. A longer time at the nest reduced the time available for collecting pollen and reduced the number of brood cells. Several interactions between parameters were important: a longer time at the nest reduced the effect of pollen per flower, a high amount of pollen per flower reduced the effect of body size to almost none, and a long time at the nest as well as a low amount of pollen per flower reduced the effect of bee density (landscape quality for bees) to almost none. For a longer foraging time (flytime), the order of importance of the discussed parameters and interactions did not change. In exceptional cases (in 5 of the 2,000 simulations), the landscape got depleted for long foraging times, and in these cases, bees built the amount of brood cells as given by $b d c$ (but not exceeding this value).

\subsubsection{Flowers Visited}

The number of visited flowers per bee was affected by body length, time at the nest, and pollen per flower. Larger bees visited more flowers, and flower visitation was also higher for a high amount of pollen per flower. A longer time at the nest decreased the number of flower visits. However, parameter interactions could change the effect. For a short time at the nest, more pollen per flower resulted in more flower visits, while for a long time at the nest more pollen per flower resulted in fewer flower visits. The aggregated number of flower visits was not separated for visits of full and empty flowers, which probably could explain some of the patterns. Visits of empty flowers must have increased for situations with increased competition pressure (such as an increased number of bees by a high amount of pollen per flower or more foraging activity by a short time at the nest). A longer foraging period did not change the importance order of the parameters.

\subsubsection{Foraging Habitat Visitation}

Foraging habitat visitation of the bee community was most affected by pollen per flower, nesting preference, landscape quality for bees, and flower density. Foraging habitat visitation (percentage of the foraging habitat visited) was higher for a higher 
amount of pollen per flower (also more bees flying around) and for soil-nesting bees (better distribution over the vegetation). A low bee density (high landscape quality for bees) decreases foraging habitat. Foraging habitat visitation by soil-nesting bees was hardly affected by foraging habitat availability, while wood-nesting bees had a lower foraging habitat visitation for a higher foraging habitat availability (parameter interaction). Apparently, wood-nesting bees in field edges were not able to cover the complete foraging habitat when there was much of it. For a longer foraging period, the effect of foraging habitat availability got more importance, and flower density lost importance. Both increase the amount of pollen and the number of bees in the landscape.

\subsubsection{Mean Distance Flown}

The mean distance flown from the nest per bee was most affected by nesting preference, body length, foraging habitat availability, time at the nest, and landscape quality for bees. Large wood-nesting bees in landscapes with a high foraging habitat availability flew the farthest. A high bee density (low landscape quality for bees) and a short time at the nest increased the mean distance flown from the nest. The effect of foraging habitat availability was low for soil-nesting bees but strong for wood-nesting bees. This parameter interaction was similar to that for foraging habitat visitation. The importance of parameters for a longer foraging period did switch for pairs with very similar importance (nest-size and bdc-ntime).

\subsubsection{Conclusions from the Second Simulation Experiment}

The analysis showed that pollen per flower ( $p p f$ ) had a disproportionate effect on the number of brood cells and interacted with body length (size). This could mean that small bees perform better on small flowers and large bees on very large flowers. However, the other performance responses did not show a strong interaction between ppf and size. The time at the nest (ntime) and landscape quality for bees (bdc) had predictable effects on the number of brood cells and showed no important interactions with other parameters. The other response variables were also affected by $p p f$, as well as by size, nest, ntime, $b d c, f d$, and $a m$.

\subsubsection{Which Body-Size-Related Traits Affect Foraging Behavior Most Strongly?}

The effect of biologically plausible parameter ranges does not give information about parameter effects close to the chosen common values. We therefore investigate the effect of small standardized changes in model parameters in this and the next simulation experiment. In this experiment, we investigate parameters related to flight and decision behavior of the bee and those related to the body size of the bee (vhi, vmed, ht, r50, sightm, flightm, CRW, pcap, cmem, ig, fmem, l_plt, u_plt). We varied each parameter by $\pm 10 \%$. For parameters that normally range between 1 and 0 , we used $0.1 \%$ increments instead of $10 \%$. We shifted for $C R W$ and $u \_p l t$ the default value by -0.1 (technical restriction). For general return distance $(r 50)$, we shifted the probability curve to the left or to the right (moving both $K m$ and shift by $10 \%$ of $r 50$ ) after $\mathrm{Km}$ and shift were calculated. Since most of the bee parameters are 
calculated from body length in different steps, we first calculated the default value and then applied the deviation (none, $-10 \%$, or $+10 \%$ ) randomly. Note that in case of ig, sightm, and flightm, there were more than three levels due to dependencies with other parameters, leading to multiple applied deviations. We generated 1,000 unique parameter sets as an alternative for generating all possible combinations. We considered wood-nesting bees of intermediate size. We repeated the analysis for soilnesting bees (altered nesting preference, 1,000 new parameter settings) and a longer foraging period (flytime $8 \mathrm{~h}$, initial 1,000 sets).

The analysis proceeded in two steps. (1) We determined which parameters were most important for variation in brood cells using a multiple regression model and checked for interactions between parameters. We simplified the linear model by minimizing the Bayesian Information Criterion (BIC). (2) We calculated the arc elasticity of the input parameters, that is, the percentage change in the response variable divided over the percentage change in input variable, measured against the average of two subsequent levels. A parameter was deemed elastic when the arc elasticity was larger than one [154, pp. 72-80]. Conversely, we considered the model parameters robust when all elasticity values remained under one. We corrected for nonsimulated parameter combinations (far more than the 1,000 simulated combinations) by predicting the response variable with the regression model. We give here an overview of the relevant effects.

\subsubsection{Importance of the Bee's Behavioral Traits in Different Situations}

The regression analysis revealed different patterns for three scenarios (wood-nesting bee, soil-nesting bee, and an elongated foraging time) in response to $10 \%$ change. Handling time per flower caused the most variation in the number of brood cells and the number of flowers visited under all three scenarios. Handling time per flower may also have prevented time being available for other activities as time at the nest did in simulation experiment 1 . For habitat visitation and distance flown, there were differences between bee types. Foraging habitat visitation was most affected by length of flight units and the mean distance flown by perception distance for woodnesting bees. For soil-nesting bees, both responses were most affected by the two patch-leaving thresholds $\left(l \_p l t, u \_p l t\right)$. Expansion over the landscape was apparently not governed by the same processes as the number of brood cells. There was no effect of a longer foraging period on any of the important predictors. Parameter interactions had a negligible effect, which means that the parameters in this experiment acted additively.

\subsubsection{Parameter Robustness of the Bee's Behavioral Traits}

Elasticity values were in general low $(<0.5)$ across the response variables (Table 10.9), which means that they were quite robust against small changes in bee-related parameters. The parameters causing most variance for each of the response variables were also causing the highest sensitivity in response (elasticity value $>0.5$ ), but never exceeded one. The highest values were for handling time per flower (both for wood- and soilnesting bees), and the model can be considered moderately robust against this parameter. A longer foraging period did slightly decrease elasticity values. Habitat visitation was most robust against changes in bee-related parameters (all values below 0.5). 


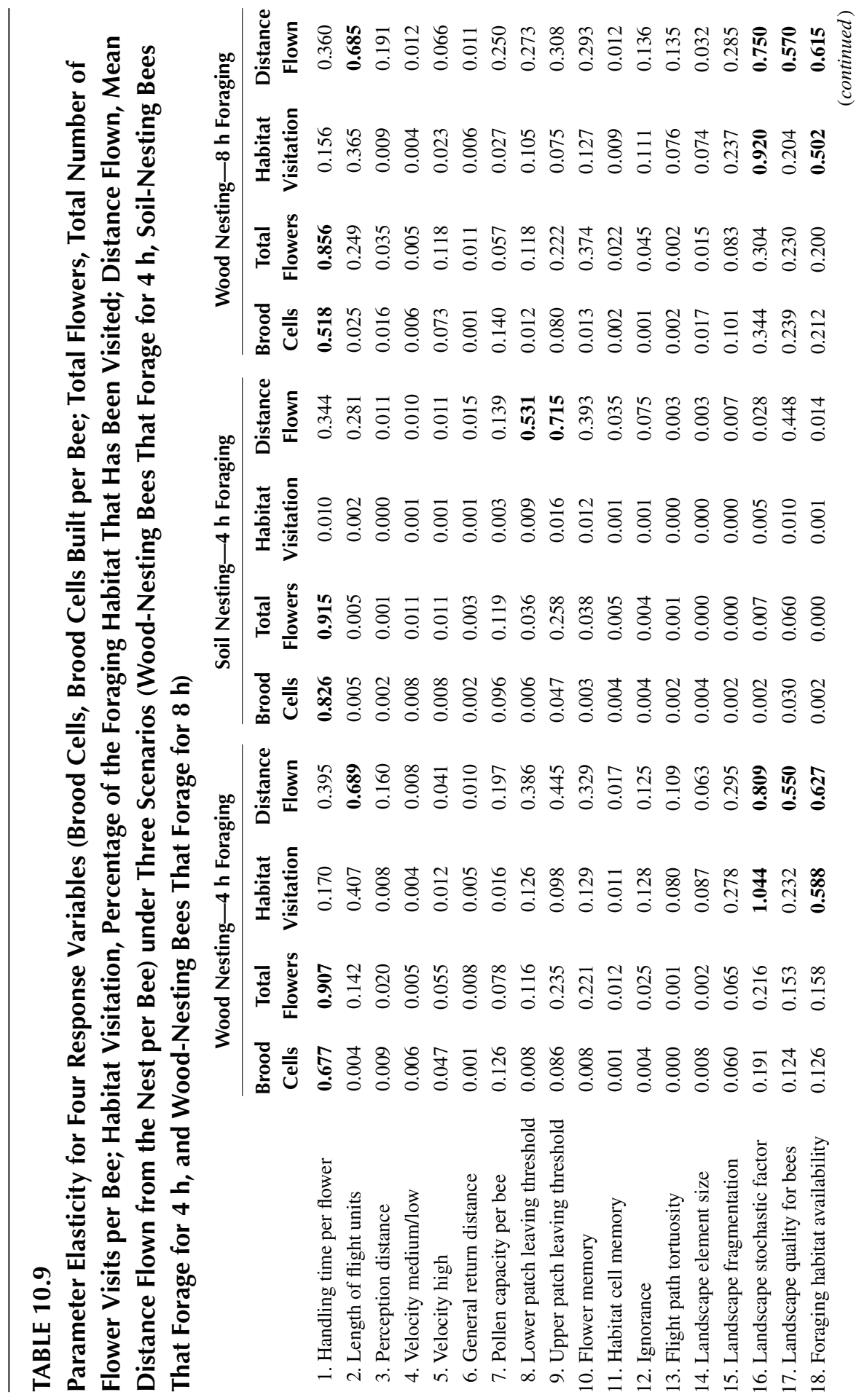




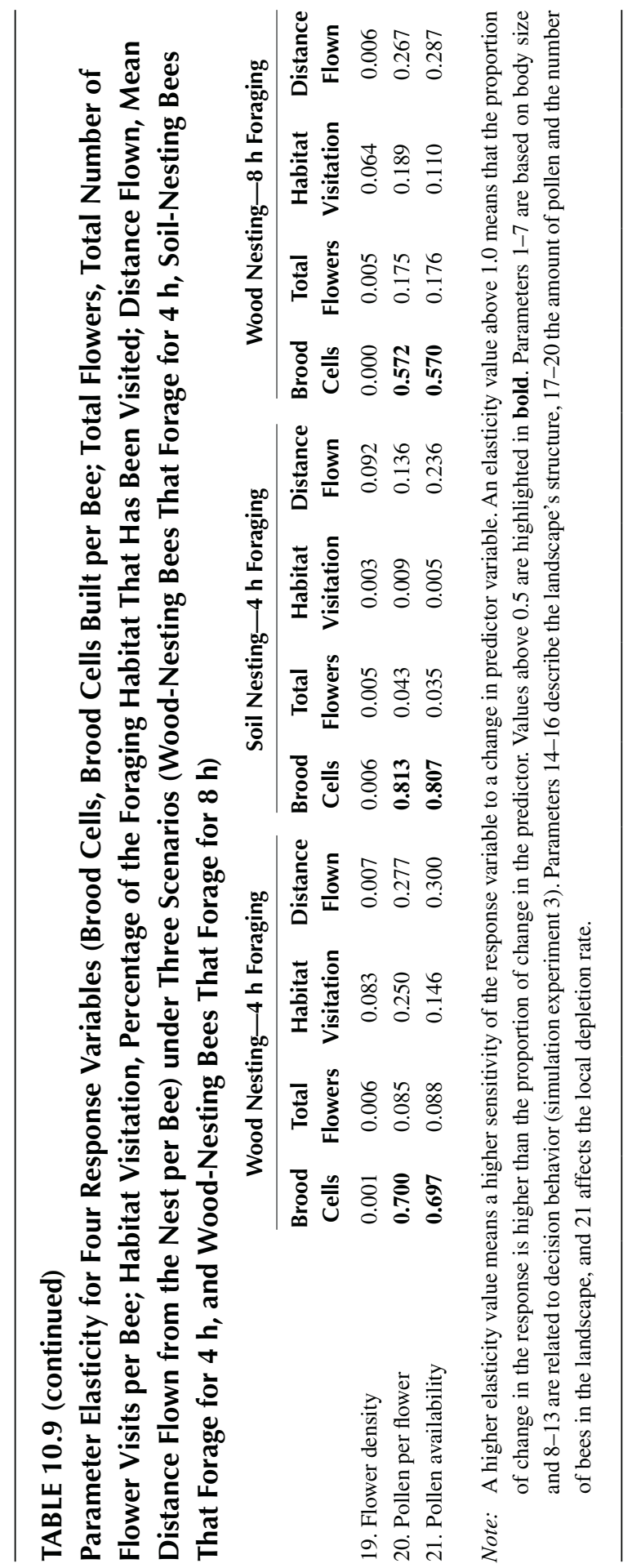




\subsubsection{How Much Do Landscape-Related Parameters Affect Solitary Bees?}

In this simulation experiment, we investigated the effect of small standardized changes in model parameters that altered the landscape and the vegetation ( $\mathrm{am}, \mathrm{fr}$, esize, seed, $b d c, f d, p p f$, plimit). We followed the same protocol as for the sensitivity of bee parameters in simulation experiment 3 .

\subsubsection{Importance of Landscape Characteristics}

The pollen per flower and pollen availability negatively affected the number of brood cells across all three scenarios (wood-nesting bee, soil-nesting bee, and a longer foraging time). Both parameters described the local vegetation properties (as well as flower density and foraging habitat availability, which only had a low impact). The other three response variables (number of flowers visited, foraging habitat visitation, and the mean distance flown) were affected by the same dominant parameter(s), which however differed for both bee types. For wood-nesting bees, foraging habitat availability and landscape stochastic factor were most important (for all three responses and for a longer foraging period). These landscape level parameters determined the spatial distribution of foraging and nesting resources. An increase in foraging habitat availability resulted in more flowers visited, a lower percentage of foraging habitat visited, and longer distances flown. For soil-nesting bees, the landscape quality for bees was important, which determined the landscape-level bee density. None of the parameter interactions had an important effect compared to the main effects.

Some of the effects seem contradictory. An increase in local resource availability (plimit, ppf) decreased the number of brood cells. An increase in foraging habitat availability increased the distance flown, but decreased the percentage of the foraging habitat visited. We suspect that local bee density around the nest (Figure 10.7) is important for these patterns and may be affected by different parameters for both bee types (wood-nesting bees responded most to $b d c$ ) and should be considered in future analyses. The landscape stochastic factor, used for adding spatial structure in the landscape generation process, had a stronger effect than landscape fragmentation and landscape element size.

\subsubsection{Parameter Robustness of Landscape Characteristics}

Elasticity for landscape parameters was also, in general, low $(<0.5)$ across the response variables, which means that they were quite robust against small changes in landscape-related parameters. The parameters causing most variance for each of the response variables were also causing the highest sensitivity in response, but values never exceeded one. Other high values were for pollen per flower and pollen availability (both for wood- and soil-nesting bees), and the model can be considered moderately robust against these parameters. A longer foraging period did slightly decrease elasticity values. The total number of flowers visited per bee was most robust against changes in landscape-related parameters.

An exception was the very high elasticity of landscape stochastic factor, exceeding one. We used the set 90-100-110 for this analysis, but the set 99-100-101 would 
lead to the same response (due to the stochastic effect of this parameter) and would reduce the elasticity values by a factor of 10 (due to $1 \%$ change instead of $10 \%$ in the independent variable). The comparison of the landscape stochastic factor with other parameters in this way appears not to be meaningful. However, it does imply that the required number of replicates for robust results still needs to be tested.

\subsection{UNDERSTANDING HOW SOLITARY BEES INTERACT WITH THE LANDSCAPE}

\subsubsection{General Conclusions}

The model produced realistic output, but our simplifications led to more efficient foraging bees that do not spend time on additional activities or unexpected conditions existing in the real world. The model seems to be driven by local bee densities (affected by vegetation parameters), time budgets (affected by performance limitations and size of the bee), and the spatial distribution of pollen and nest locations, which affected the response variables differently. The model seems to be suitable to explore further ecological questions dealing with pollen-collecting solitary bees.

Different species of solitary bees clearly responded differently to landscape features. It was a remarkable result that wood-nesting bees that nest in field edges performed worse when there were more foraging resources. Wood-nesting bees needed to fly farther from the nest and were therefore under certain conditions more time limited than other bees and built fewer brood cells. Body size also had a large impact on performance (brood cells, flowers visited, foraging distance), but bees of different size did in general respond qualitatively similar to other parameter changes. From all size-related traits, handling time per flower has had the most effect on the bee's performance. The amount of pollen per flower and landscape quality for bees had a very strong effect as well, by affecting the number of bees in the landscape. Despite strong and some unexpected effects in the model, all parameters were robust against small changes.

The simulation experiments showed that the selection of values for some parameters deserves more attention for selection than others. The most uncertain and unknown parameters (sightm, flightm, CRW, fmem, cmem) did not have strong effects on the response variables and do not require further study. The strong effect of pollen per flower ( $p p f$ ) suggests that the model is suitable for comparing different vegetation types such as fields of clover (little pollen) and fields of sunflowers (very much pollen). However, the model does require very long running times for large flowers (resources for millions of bees), making such comparisons unattractive. Alternatively, one can also consider meadow-like vegetation with moderately sized flowers (moderate pollen production) as a legitimate and realistic scenario for future simulations, since large flowers are not common in most landscapes. The time-budget parameters time at the nest and foraging time (flytime) affected the responses, but they did not affect the relative impact of other parameters. We suggest a moderate value for time at the nest, since it is biologically more plausible. A value of $4 \mathrm{~h}$ as foraging time is just as suitable as $8 \mathrm{~h}$ to measure performance within a foraging day and saves simulation time. We also consider the selected value for bdc (landscape 
quality for bees) as biologically more plausible than its extremes (see Section 10.3.1). The other important parameters body length, nesting preference, and foraging habitat availability should be incorporated in all future simulation experiments.

\subsubsection{General Interest and Limitations}

The main strength of the model is its high level of realism. In such a mechanistic model, all essential processes are controllable with parameters, which enables investigation of each parameter independently. This can be especially valuable in ecology, since it can rule out variance present in field experiments. In ecological field experiments, it is often impossible to regulate all environmental conditions independently. All of the parameters can potentially be measured, and none of the parameters has an abstract meaning, which make the model suitable for many applications. The main response simulated (brood cells) is also very direct. It registers the direct performance of the bee in amount of pollen that can be collected in a certain amount of time, which is a relative novel approach for the ecology of bees. Most studies at the landscape scale deal with aggregated responses such as species numbers and individual numbers, while the model can study the potential offspring (brood cells) for a certain bee species in a certain landscape.

We experienced also some limitations. The many parameters in the model introduce uncertainty. We have put substantial effort in reducing these parameter uncertainties by extensive literature review (Section 10.3.1), effect exploration (simulation experiment 1), and sensitivity analysis (simulation experiments 2,3 , and 4), but this did not inform us about all uncertainties. We did, for example, test what the consequences would be if each of the bee traits would be $10 \%$ higher or lower than that estimated by the scaling relationship (simulation experiment 3), but we did not test what consequences altered scaling relations would have (possibly leading to larger deviations than $10 \%$ for small or large bees). In addition to this, we ignored that some parameters could scale with body size as well (but have not been shown yet to do so for bees or similar insects), such as for time at the nest, the perceived grain size, and the preference for a certain flower size (pollen per flower). The model design not only involved assumptions based on observations, but some were also made for simplifying reasons. The model assumed that small and large bees use the same proportion of their flower visiting time for pollen collection, that male and female cells are built in equal ratio (mean number of trips required per cell was applied as fixed value), and that bees choose to nest near their foraging resource. These simplifications may have caused that the model bees were more efficient than real bees (Section 10.4.1.2).

Ideally, we would like to validate the model for fixed positions in the parameter space, but the field data only allowed us to show that their ranges overlap well with the model's response variables. The response variable "brood cells" (per individual, per day) is difficult to link to field studies since most studies give the number of brood cells per trap nest (undefined number of individuals) or per lifetime (undefined number of days). Further, most experimental studies have measured only a fraction of the parameters used as input for the model, and up to now there was no complete set of environmental parameters available for the model. This is another clear disadvantage of a large number of parameters. Some of the important parameters such as 
flower density and activity time of the bee could be measured, but no single study at the landscape level did so far. Other parameters, such as the local bee density in the environment or the amount of pollen per flower, may be hard to measure accurately in the field. A suggestion is to roughly estimate the parameters for field studies to get a complete set of parameters. Landscape parameters can be assessed from land-use maps validated by field surveys and be completed with estimated flower densities for each land-use class. A more difficult-to-measure parameter such as pollen production per flower could be approximated by flower size. The bee's body length can be measured in the field as well and serve as proxy for behavioral foraging traits. Measuring such values in the field and using them as input for the model to simulate specific situations have a high potential for understanding observed field patterns.

In general, more field research would benefit the model. Fundamental and descriptive ecological research could strengthen theoretical relationships between body size and traits that affect time budgets. Measurement efforts to assess or at least estimate the complete set of parameters for several example landscapes would strengthen further model validation. However, due to the labor-intensive nature of parameter assessment in the field, such measurements are restricted by financial resources. This financial issue would favor applying the model in its current state, since it is quite elaborate already. In the case of future application of the model, it is important to ask whether it is acceptable that the model simulates more efficient bees than in real systems (e.g., by nesting close to their foraging resource) and whether it is of minor importance for the specific research question.

\subsubsection{OutLook}

We found several interesting results that are worth exploring further, mainly concerning bee type and landscape structure. Soil-nesting and wood-nesting bees responded differently to landscape structure, and body size also affected performance. Species differ, and systematic simulations could help to find out how their performance differs in different landscapes and what the causes are. Both the spatial resource distribution of pollen and nest locations influence how bees behave in the model, and they determine depletion patterns. How does fragmentation of the spatial patch mosaic influence the interaction between bees and their performance? How do bee size, nesting preference, and landscape structure affect pollination services?

Finally, the model has the potential to study other topics and learn more about bee biology. What is, for example, the effect of different foraging trade-offs? How do handling time, pollen requirements, number of flower visits, and patch-size selection affect one another? Are there optimal strategies concerning different "giving up times" at the flower and the patch level? Can bees of different size optimize their foraging behavior by choosing an optimal flower size?

\section{ACKNOWLEDGMENTS}

This study was supported by the European Commission within FP 6 Integrated Project ALARM: Assessing LArge scale environmental Risks with tested Methods (GOCE-CT-2003-506675), the Helmholtz Association (VH-NG 247), 
and the Helmholtz Impulse and Networking Fund through HIGRADE: Helmholtz Interdisciplinary Graduate School for Environmental Research. We thank Volker Grimm for helpful comments on this chapter.

\section{REFERENCES}

1. M.A. Aizen, L.A. Garibaldi, S.A. Cunningham, and A.-M. Klein, How much does agriculture depend on pollinators? Lessons from long-term trends in crop production, Ann. Bot. 103 (2009), pp. 1579-1588.

2. C.D. Michener, The Bees of the World, Johns Hopkins University Press, Baltimore, MD, 2000.

3. J.L. Neff, Components of nest provisioning behavior in solitary bees (Hymenoptera: Apoidea), Apidologie 39 (2008), pp. 30-45.

4. M. Chagnon, J. Gingras, and D. Deoliveira, Complementary aspects of strawberry pollination by honey and indigenous bees (Hymenoptera), J. Econ. Entomol. 86 (1993), pp. 416-420.

5. A.-M. Klein, I. Steffan-Dewenter, and T. Tscharntke, Fruit set of highland coffee increases with the diversity of pollinating bees, Proceed. Royal Soc. Lond. B: Biol. Sci. 270 (2003), pp. 955-961.

6. M.A. Aizen and P. Feinsinger, Habitat fragmentation, native insect pollinators, and feral honey-bees in Argentine Chaco Serrano, Ecol. Appl. 4 (1994), pp. 378-392.

7. E. Andrieu, A. Dornier, S. Rouifed, B. Schatz, and P.-O. Cheptou, The town Crepis and the country Crepis: How does fragmentation affect a plant-pollinator interaction? Acta Oecol. 35 (2009), pp. 1-7.

8. G.H. Pyke, Animal movements: An optimal foraging approach, in The Ecology of Animal Movement, J.R. Swingland and P.J. Greenwood, eds., Oxford University Press, Oxford, UK, 1983, pp. 7-31.

9. E.G. Linsley, The ecology of solitary bees, Hilgardia 27 (1958), pp. 543-599.

10. C. Westerkamp, Honeybees are poor pollinators—Why? Plant Syst. Evol. 177 (1991), pp. 71-75.

11. N.R.C. Committee on the Status of Pollinators in North America, Status of Pollinators in North America, The National Academies Press, Washington, DC, 2007.

12. I.H. Williams, Insect pollination and crop production: A European perspective, in Pollinating Bees-The Conservation Link between Agriculture and Nature, P.G. Kevan and V.L. Imperatriz-Fonseca, eds., Ministry of Environment, Brasília, Brazil, 2002, pp. 59-65.

13. I. Steffan-Dewenter, S.G. Potts, and L. Packer, Pollinator diversity and crop pollination services are at risk, Trends Ecol. Evol. 20 (2005), pp. 651-652.

14. S.H.M.Butchart, M.Walpole, B.Collen,A.van Strien,J.P.W.Scharlemann, R.E.A.Almond, J.E.M. Baillie, B. Bomhard, C. Brown, J. Bruno, K.E. Carpenter, G.M. Carr, J. Chanson, A.M. Chenery, J. Csirke, N.C. Davidson, F. Dentener, M. Foster, A. Galli, J.N. Galloway, P. Genovesi, R.D. Gregory, M. Hockings, V. Kapos, J.F. Lamarque, F. Leverington, J. Loh, M.A. McGeoch, L. McRae, A. Minasyan, M.H. Morcillo, T.E.E. Oldfield, D. Pauly, S. Quader, C. Revenga, J.R. Sauer, B. Skolnik, D. Spear, D. Stanwell-Smith, S.N. Stuart, A. Symes, M. Tierney, T.D. Tyrrell, J.C. Vie, and R. Watson, Global biodiversity: Indicators of recent declines, Science 328 (2010), pp. 1164-1168.

15. T.D. Breeze, A.P. Bailey, K.G. Balcombe, and S.G. Potts, Pollination services in the UK: How important are honeybees? Agric. Ecosyst. Environ. 142 (2011), pp. 137-143.

16. L.A. Garibaldi, I. Steffan-Dewenter, C. Kremen, J.M. Morales, R. Bommarco, S.A. Cunningham, L.G. Carvalheiro, N.P. Chacoff, J.H. Dudenhoffer, S.S. Greenleaf, A. Holzschuh, R. Isaacs, K. Krewenka, Y. Mandelik, M.M. Mayfield, L.A. Morandin, 
S.G. Potts, T.H. Ricketts, H. Szentgyörgyi, B.F. Viana, C. Westphal, R. Winfree, and A.-M. Klein, Stability of pollination services decreases with isolation from natural areas despite honey bee visits, Ecol. Lett. 14 (2011), pp. 1062-1072.

17. L.G. Carvalheiro, C.L. Seymour, R. Veldtman, and S.W. Nicolson, Pollination services decline with distance from natural habitat even in biodiversity-rich areas, J. Appl. Ecol. 47 (2010), pp. 810-820.

18. T.H. Ricketts, J. Regetz, I. Steffan-Dewenter, S.A. Cunningham, C. Kremen, A. Bogdanski, B. Gemmill-Herren, S.S. Greenleaf, A.-M. Klein, M.M. Mayfield, L.A. Morandin, A. Ochieng', S.G. Potts, and B.F. Viana, Landscape effects on crop pollination services: Are there general patterns? Ecol. Lett. 11 (2008), pp. 499-515.

19. C. Kremen, N.M. Williams, R.L. Bugg, J.P. Fay, and R.W. Thorp, The area requirements of an ecosystem service: Crop pollination by native bee communities in California, Ecol. Lett. 7 (2004), pp. 1109-1119.

20. S.A. Corbet, I.H. Williams, and J.L. Osborne, Bees and the pollination of crops and wild flowers in the European community, Bee World 72 (1991), pp. 47-59.

21. S.G. Potts, J.C. Biesmeijer, C. Kremen, P. Neumann, O. Schweiger, and W.E. Kunin, Global pollinator declines: Trends, impacts and drivers, Trends Ecol. Evol. 25 (2010), pp. 345-353.

22. J.C. Biesmeijer, S.P.M. Roberts, M. Reemer, R. Ohlemüller, M. Edwards, T. Peeters, A.P. Schaffers, S.G. Potts, R. Kleukers, C.D. Thomas, J. Settele, and W.E. Kunin, Parallel declines in pollinators and insect-pollinated plants in Britain and the Netherlands, Science 313 (2006), pp. 351-354.

23. P. Neumann and N.L. Carreck, Honey bee colony losses, J. Apic. Res. 49 (2010), pp. 1-6.

24. D. van Engelsdorp, J.D. Evans, C. Saegerman, C. Mullin, E. Haubruge, B.K. Nguyen, M. Frazier, J. Frazier, D. Cox-Foster, Y.P. Chen, R.M. Underwood, D.R. Tarpy, and J.S. Pettis, Colony collapse disorder: A descriptive study, PLoS ONE 4 (2009), p. e6481.

25. M.E. Knight, J.L. Osborne, R.A. Sanderson, R.J. Hale, A.P. Martin, and D. Goulson, Bumblebee nest density and the scale of available forage in arable landscapes, Insect Conserv. Divers. 2 (2009), pp. 116-124.

26. C.A. Kearns, D.W. Inouye, and N.M. Waser, Endangered mutualisms: The conservation of plant-pollinator interactions, Annu. Rev. Ecol. Syst. 29 (1998), pp. 83-112.

27. J.H. Cane and V.J. Tepedino, Causes and extent of declines among native North American invertebrate pollinators: Detection, evidence, and consequences, Conserv. Ecol. 5 (2001). Available at http://www.consecol.org/vol5/iss1/art1/.

28. T. Tscharntke and R. Brandl, Plant-insect interactions in fragmented landscapes, Annu. Rev. Entomol. 49 (2004), pp. 405-430.

29. E. Lonsdorf, C. Kremen, T.H. Ricketts, R. Winfree, N.M. Williams, and S.S. Greenleaf, Modelling pollination services across agricultural landscapes, Ann. Bot. 103 (2009), pp. $1589-1600$.

30. J. Banaszak, Effect of habitat heterogeneity on the diversity and density of pollinating insects, in Interchanges of Insects between Agricultural and Surrounding Landscapes, B.S. Ekbom, M.E. Irwin, and Y. Robert, eds., Kluwer Academic, Dordrecht, the Netherlands, 2000, pp. 123-140.

31. L.D. Harder and W.G. Wilson, Theoretical consequences of heterogeneous transport conditions for pollen dispersal by animals, Ecology 79 (1998), pp. 2789-2807.

32. R.B. Aronson and T.J. Givnish, Optimal central-place foragers-A comparison with null hypotheses, Ecology 64 (1983), pp. 395-399.

33. F. Thuijsman, B. Peleg, M. Amitai, and A. Shmida, Automata, matching and foraging behavior of bees, J. Theor. Biol. 175 (1995), pp. 305-316.

34. J.E. Cresswell, A mechanistic model of pollinator-mediated gene flow in agricultural safflower, Basic Appl. Ecol. 11 (2010), pp. 415-421. 
35. R. Dukas and L. Edelstein-Keshet, The spatial distribution of colonial food provisioners, J. Theor. Biol. 190 (1998), pp. 121-134.

36. C. Westphal, I. Steffan-Dewenter, and T. Tscharntke, Foraging trip duration of bumblebees in relation to landscape-wide resource availability, Ecol. Entomol. 31 (2006), pp. 389-394.

37. K. Ulbrich and K. Seidelmann, Modeling population dynamics of solitary bees in relation to habitat quality, Web Ecol. 2 (2001), pp. 57-64.

38. D. Austin, W.D. Bowen, and J.I. McMillan, Intraspecific variation in movement patterns: Modeling individual behaviour in a large marine predator, Oikos 105 (2004), pp. $15-30$.

39. V. Grimm and S.F. Railsback, Individual-Based Modeling and Ecology, Princeton Series in Theoretical and Computational Biology, Princeton University Press, Princeton, NJ, 2005.

40. V. Grimm, U. Berger, F. Bastiansen, S. Eliassen, V. Ginot, J. Giske, J. Goss-Custard, T. Grand, S.K. Heinz, G. Huse, A. Huth, J.U. Jepsen, C. Jørgensen, W.M. Mooij, B. Müller, G. Pe'er, C. Piou, S.F. Railsback, A.M. Robbins, M.M. Robbins, E. Rossmanith, N. Rüger, E. Strand, S. Souissi, R.A. Stillman, R. Vabø, U. Visser, and D.L. DeAngelis, A standard protocol for describing individual-based and agent-based models, Ecol. Model. 198 (2006), pp. 115-126.

41. V. Grimm, U. Berger, D.L. DeAngelis, J.G. Polhill, J. Giske, and S.F. Railsback, The ODD protocol A review and first update, Ecol. Model. 221 (2010), pp. 2760-2768.

42. R.M. Ewers and R.K. Didham, Confounding factors in the detection of species responses to habitat fragmentation, Biol. Rev. 81 (2006), pp. 117-142.

43. I. Steffan-Dewenter, U. Münzenberg, and T. Tscharntke, Pollination, seed set and seed predation on a landscape scale, Proc. Royal Soc. Lond. Ser. B: Biol. Sci. 268 (2001), pp. $1685-1690$.

44. N.M. Williams and V.J. Tepedino, Consistent mixing of near and distant resources in foraging bouts by the solitary mason bee Osmia lignaria, Behav. Ecol. 14 (2003), pp. 141-149.

45. V. Monsevičius, Fauna of wild bees in Lithuania and trends of its changes, in Changes in Fauna of Wild Bees in Europe, J. Banaszak, ed., Pedagogical University, Bydgoszcz, Poland, 1995, pp. 27-39.

46. M. Franzén, M. Larsson, and S.G. Nilsson, Small local population sizes and high habitat patch fidelity in a specialised solitary bee, J. Insect. Conserv. 13 (2009), pp. 89-95.

47. D.R. Artz and K.D. Waddington, The effects of neighbouring tree islands on pollinator density and diversity, and on pollination of a wet prairie species, Asclepias lanceolata (Apocynaceae), J. Ecol. 94 (2006), pp. 597-608.

48. T. Diekötter, K.J. Haynes, D. Mazeffa, and T.O. Crist, Direct and indirect effects of habitat area and matrix composition on species interactions among flower-visiting insects, Oikos 116 (2007), pp. 1588-1598.

49. J. Joshi, P. Stoll, H.P. Rusterholz, B. Schmid, C. Dolt, and B. Baur, Small-scale experimental habitat fragmentation reduces colonization rates in species-rich grasslands, Oecologia 148 (2006), pp. 144-152.

50. E.L. Charnov, Optimal foraging, marginal value theorem, Theor. Popul. Biol. 9 (1976), pp. 129-136.

51. A. Basset, M. Fedele, and D.L. DeAngelis, Optimal exploitation of spatially distributed trophic resources and population stability, Ecol. Model. 151 (2002), pp. 245-260.

52. U. Motro and A. Shmida, Near-far search-An evolutionarily stable foraging strategy, J. Theor. Biol. 173 (1995), pp. 15-22.

53. M. Beil, H. Horn, and A. Schwabe, Analysis of pollen loads in a wild bee community (Hymenoptera: Apidae)—A method for elucidating habitat use and foraging distances, Apidologie 39 (2008), pp. 456-467. 
54. B. Heinrich, Majoring and minoring by foraging bumblebees, Bombus vagansExperimental analysis, Ecology 60 (1979), pp. 245-255.

55. G.C. Eickwort and H.S. Ginsberg, Foraging and mating-behavior in Apoidea, Annu. Rev. Entomol. 25 (1980), pp. 421-446.

56. R. Campan and M. Lehrer, Discrimination of closed shapes by two species of bee, Apis mellifera and Megachile rotundata, J. Exp. Biol. 205 (2002), pp. 559-572.

57. D. Saupe, Algorithms for random fractals, in The Sciences of Fractal Images, H.-O. Peitgen and D. Saupe, eds., Springer-Verlag, New York, 1988, pp. 71-113.

58. K.A. With, R.H. Gardner, and M.G. Turner, Landscape connectivity and population distributions in heterogeneous environments, Oikos 78 (1997), pp. 151-169.

59. C.D. Hargis, J.A. Bissonette, and J.L. David, The behavior of landscape metrics commonly used in the study of habitat fragmentation, Landscape Ecol. 13 (1998), pp. 167-186.

60. J.H. Cane, Estimation of bee size using intertegular span (Apoidea), J. Kans. Entomol. Soc. 60 (1987), pp. 145-147.

61. A. Müller, S. Diener, S. Schnyder, K. Stutz, C. Sedivy, and S. Dorn, Quantitative pollen requirements of solitary bees: Implications for bee conservation and the evolution of bee-flower relationships, Biol. Conserv. 130 (2006), pp. 604-615.

62. S.S. Greenleaf, N.M. Williams, R. Winfree, and C. Kremen, Bee foraging ranges and their relationship to body size, Oecologia 153 (2007), pp. 589-596.

63. I. Calabuig, Solitary bees and bumblebees in a Danish agricultural landscape, Ph.D. diss., University of Copenhagen, Copenhagen, Denmark, 2000.

64. A. Gathmann, H.J. Greiler, and T. Tscharntke, Trap-nesting bees and wasps colonizing set-aside fields-Succession and body-size, management by cutting and sowing, Oecologia 98 (1994), pp. 8-14.

65. T. Pawlikowski, Struktura zgrupowań dzikich pszczołowatych (Hymenoptera, Apoidea) z obszarów rolnych o różnych typach parcelacji powierzchni uprawnej. [The structure of wild bee (Hymenoptera, Apoidea) communities from farming areas of different field sizes], Acta Univ. Nic. Copernici, Biol. 33 (1989), pp. 31-46.

66. P. Westrich, Habitat requirements of central European bees and the problems of partial habitats, in The Conservation of Bees, A. Matheson, S.L. Buchmann, C. O'Toole, P. Westrich, and I.H. Williams, eds., Academic Press, London, UK, 1996, pp. 1-16.

67. S. Kirkpatrick and E.P. Stoll, A very fast shift-register sequence random number generator, J. Comput. Phys. 40 (1981), pp. 517-526.

68. D.P. Abrol and R.P. Kapil, On homing ability and pollination effectiveness of bees, Mysore J. Agric. Sci. 28 (1994), pp. 249-252.

69. V. Grimm, E. Revilla, U. Berger, F. Jeltsch, W.M. Mooij, S.F. Railsback, H.H. Thulke, J. Weiner, T. Wiegand, and D.L. DeAngelis, Pattern-oriented modeling of agent-based complex systems: Lessons from ecology, Science 310 (2005), pp. 987-991.

70. T. Wiegand, F. Jeltsch, I. Hanski, and V. Grimm, Using pattern-oriented modeling for revealing hidden information: A key for reconciling ecological theory and application, Oikos 100 (2003), pp. 209-222.

71. N.M. Williams and C. Kremen, Resource distributions among habitats determine solitary bee offspring production in a mosaic landscape, Ecol. Appl. 17 (2007), pp. 910-921.

72. K. Szklanowska, Pollen flows of crowfoot family (Ranunculaceae) from some natural plant communities, in Changes in Fauna of Wild Bees in Europe, J. Banaszak, ed., Pedagogical University, Bydgoszcz, Poland, 1995, pp. 201-214.

73. B. Denisow, Blooming and pollen production of several representatives of the genus Centaurea L, J. Apicult. Sci. 50 (2006), pp. 13-20.

74. Z. Kołtowski, The effect of pollinating insects on the yield of winter rapeseed (Brassica napus L. var. napus f. biennis) cultivars, J. Apicult. Sci. 49 (2005), pp. 29-41. 
75. K.D. Waddington, Foraging patterns of Halictid bees at flowers of Convolvulus arvensis, Psyche 83 (1976), pp. 112-119.

76. L.D. Harder, Pollen-size comparisons among animal-pollinated angiosperms with different pollination characteristics, Biol. J. Linn. Soc. 64 (1998), pp. 513-525.

77. R. Gallardo, E. Dominguez, and J.M. Munoz, Pollen ovule ratio, pollen size, and breeding system in Astragalus (Fabaceae) subgenus Epiglottis-A pollen and seed allocation approach, Am. J. Bot. 81 (1994), pp. 1611-1619.

78. B. Denisow and M. Bozek, Blooming and pollen production of two Lamium L. species, J. Apicult. Sci. 52 (2008), pp. 21-30.

79. C. Erbar and P. Leins, Portioned pollen release and the syndromes of secondary pollen presentation in the Campanulales-Asterales-complex, Flora 190 (1995), pp. 323-338.

80. L.D. Harder, Behavioral responses by bumble bees to variation in pollen availability, Oecologia 85 (1990), pp. 41-47.

81. L.D. Harder, Pollen removal by bumble bees and its implications for pollen dispersal, Ecology 71 (1990), pp. 1110-1125.

82. D.S. Willis and P.G. Kevan, Foraging dynamics of Peponapis pruinosa (Hymenoptera, Anthophoridae) on pumpkin (Cucurbita pepo) in southern Ontario, Can. Entomol. 127 (1995), pp. 167-175.

83. C. Schlindwein, D. Wittmann, C.F. Martins, A. Hamm, J.A. Siqueira, D. Schiffler, and I.C. Machado, Pollination of Campanula rapunculus L. (Campanulaceae): How much pollen flows into pollination and into reproduction of oligolectic pollinators? Plant Syst. Evol. 250 (2005), pp. 147-156.

84. S.S. Greenleaf and C. Kremen, Wild bees enhance honey bees' pollination of hybrid sunflower, Proc. Nat. Acad. Sci. USA. 103 (2006), pp. 13890-13895.

85. P. Hoehn, T. Tscharntke, J.M. Tylianakis, and I. Steffan-Dewenter, Functional group diversity of bee pollinators increases crop yield, Proc. Royal Soc. B: Biol. Sci. 275 (2008), pp. 2283-2291.

86. J. Banaszak, Natural resources of wild bees in Poland and an attempt at estimation of their changes, in Changes in Fauna of Wild Bees in Europe, J. Banaszak, ed., Pedagogical University, Bydgoszcz, Poland, 1995, pp. 9-25.

87. J. Bosch, The nesting behaviour of the mason bee Osmia cornuta (Latr) with special reference to its pollinating potential (Hymenoptera, Megachilidae), Apidologie 25 (1994), pp. 84-93.

88. M. Franzén and M. Larsson, Pollen harvesting and reproductive rates in specialized solitary bees, Ann. Zool. Fenn. 44 (2007), pp. 405-414.

89. M. Giovanetti and E. Lasso, Body size, loading capacity and rate of reproduction in the communal bee Andrena agilissima (Hymenoptera; Andrenidae), Apidologie 36 (2005), pp. 439-447.

90. M. Larsson and M. Franzén, Critical resource levels of pollen for the declining bee Andrena hattorfiana (Hymenoptera, Andrenidae), Biol. Conserv. 134 (2007), pp. 405-414.

91. J.L. Neff and B.N. Danforth, The nesting and foraging behavior of Perdita texana (Cresson) (Hymenoptera, Andrenidae), J. Kans. Entomol. Soc. 64 (1991), pp. 394-405.

92. J. Kunze and L. Chittka, Bees and butterflies fly faster when plants feed them more nectar, in Goettingen Neurobiology Report 1996, N. Elsner and H. Schnitzler, eds., Thieme Verlag, Stuttgart, Germany, 1996, pp. 109-109.

93. A. Barron and M.V. Srinivasan, Visual regulation of ground speed and headwind compensation in freely flying honey bees (Apis mellifera L.), J. Exp. Biol. 209 (2006), pp. 978-984.

94. W. Nachtigall, U. Hanauer-Thieser, and M. Morz, Flight of the honey bee. 7. Metabolic power versus flight speed relation, J. Comp. Physiol. B: Biochem. System. Environ. Physiol. 165 (1995), pp. 484-489. 
95. C.P. Ellington, K.E. Machin, and T.M. Casey, Oxygen-consumption of bumblebees in forward flight, Nature 347 (1990), pp. 472-473.

96. A.B. Ware and S.G. Compton, Dispersal of adult female fig wasps. 2. Movements between trees, Entomol. Exp. Appl. 73 (1994), pp. 231-238.

97. S.G. Compton, M.D.F. Ellwood, A.J. Davis, and K. Welch, The flight heights of chalcid wasps (Hymenoptera, Chalcidoidea) in a lowland Bornean rain forest: Fig wasps are the high fliers, Biotropica 32 (2000), pp. 515-522.

98. C. Guédot, J. Bosch, and W.P. Kemp, Relationship between body size and homing ability in the genus Osmia (Hymenoptera; Megachilidae), Ecol. Entomol. 34 (2009), pp. 158-161.

99. W. Nachtigall, Formation of clay globules and flight departure with the building material by the thread-waisted potter wasp Sceliphron spirifex (Hymenoptera: Sphecidae), Entomol. Gen. 25 (2001), pp. 161-170.

100. T.J. Dean, Chapter 1: Fastest flyer, in University of Florida Book of Insect Record. Available at http://entomology.ifas.ufl.edu/walker/ufbir.

101. R. Piper, Extraordinary Animals: An Encyclopedia of Curious and Unusual Animals, Greenwood Press, Westport, CT, 2007.

102. K. Strickler, Specialization and foraging efficiency of solitary bees, Ecology 60 (1979), pp. 998-1009.

103. N.E. Raine and L. Chittka, Pollen foraging: Learning a complex motor skill by bumblebees (Bombus terrestris), Naturwissenschaften 94 (2007), pp. 459-464.

104. H.J. Young and M.L. Stanton, Influences of floral variation on pollen removal and seed production in wild radish, Ecology 71 (1990), pp. 536-547.

105. U. Jander and R. Jander, Allometry and resolution of bee eyes (Apoidea), Arthr. Struct. Dev. 30 (2002), pp. 179-193.

106. A. Dafni and P.G. Kevan, Hypothesis on adaptive features of the compound eye of bees-Flower-specific specializations, Evol. Ecol. 9 (1995), pp. 236-241.

107. M.V. Srinivasan, S.W. Zhang, M. Lehrer, and T.S. Collett, Honeybee navigation en route to the goal: Visual flight control and odometry, J. Exp. Biol. 199 (1996), pp. 237-244.

108. J.R. Riley, D.R. Reynolds, A.D. Smith, A.S. Edwards, J.L. Osborne, I.H. Williams, and H.A. McCartney, Compensation for wind drift by bumble-bees, Nature 400 (1999), p. 126.

109. L. Chittka, N.M. Williams, H. Rasmussen, and J.D. Thomson, Navigation without vision: Bumblebee orientation in complete darkness, Proc. Royal Soc. Lond. Ser. B: Biol. Sci. 266 (1999), pp. 45-50.

110. R. Menzel, Behavioral and neural mechanisms of learning and memory as determinants of flower constancy, in Cognitive Ecology of Pollination, L. Chittka and J.D. Thomson, eds., Cambridge University Press, Cambridge, UK, 2001, pp. 21-40.

111. G. Ne'eman, O. Shavit, L. Shaltiel, and A. Shmida, Foraging by male and female solitary bees with implications for pollination, J. Insect. Behav. 19 (2006), pp. 383-401.

112. L. Chittka and N.E. Raine, Recognition of flowers by pollinators, Curr. Opin. Plant Biol. 9 (2006), pp. 428-435.

113. R. Menzel, R. Brandt, A. Gumbert, B. Komischke, and J. Kunze, Two spatial memories for honeybee navigation, Proc. Royal Soc. Lond. Ser. B: Biol. Sci. 267 (2000), pp. 961-968.

114. A.H. Powell and G.V.N. Powell, Population-dynamics of male Euglossine bees in Amazonian forest fragments, Biotropica 19 (1987), pp. 176-179.

115. P. Schmid-Hempel, How do bees choose flight direction while foraging, Physiol. Entomol. 10 (1985), pp. 439-442.

116. T.T. Makino, K. Ohashi, and S. Sakai, How do floral display size and the density of surrounding flowers influence the likelihood of bumble bee revisitation to a plant? Funct. Ecol. 21 (2007), pp. 87-95. 
117. R.V. Cartar and L.A. Real, Habitat structure and animal movement: The behaviour of bumble bees in uniform and random spatial resource distributions, Oecologia 112 (1997), pp. 430-434.

118. B. Heinrich, Resource heterogeneity and patterns of movement in foraging bumblebees, Oecologia 40 (1979), pp. 235-245.

119. A.M. Reynolds, A.D. Smith, R. Menzel, U. Greggers, D.R. Reynolds, and J.R. Riley, Displaced honey bees perform optimal scale-free search flights, Ecology 88 (2007), pp. 1955-1961.

120. H. Teppner, Bienen und Obstbaum-Bestäubung, Obst Wein Garten 65 (1996), pp. 3-7.

121. B.N. Danforth, Provisioning behavior and the estimation of investment ratios in a solitary bee, Calliopsis (Hypomacrotera) persimilis (Cockerell) (Hymenoptera: Andrenidae), Behav. Ecol. Sociobiol. 27 (1990), pp. 159-168.

122. J.-N. Tasei, Le comportement de nidification chez Osmia (Osmia) cornuta Latr. et Osmia (Osmia) rufa L. (Hymenoptera Megachilidae), Apidologie 4 (1973), pp. 195-225.

123. E.G. Linsley, Temporal patterns of flower visitation by solitary bees, with particular reference to the southwestern United States, J. Kans. Entomol. Soc. 51 (1978), pp. 531-546.

124. J. Bosch and M. Blas, Foraging behavior and pollinating efficiency of Osmia cornuta and Apis mellifera on almond (Hymenoptera, Megachilidae and Apidae), Appl. Entomol. Zool. 29 (1994), pp. 1-9.

125. G.N. Stone, Patterns of evolution of warm-up rates and body temperatures in-flight in solitary bees of the genus Anthophora, Funct. Ecol. 8 (1994), pp. 324-335.

126. P.G. Willmer and G.N. Stone, Behavioral, ecological, and physiological determinants of the activity patterns of bees, Adv. Study Behav. 34 (2004), pp. 347-466.

127. W.J. Bell, Searching behavior patterns in insects, Annu. Rev. Entomol. 35 (1990), pp. $447-467$.

128. J.D. Thomson and L. Chittka, Pollinator individuality: When does it matter? in Cognitive Ecology of Pollination, L. Chittka and J.D. Thomson, eds., Cambridge University Press, Cambridge, UK, 2001, pp. 191-213.

129. M.J. Couvillon, G. DeGrandi-Hoffman, and W. Gronenberg, Africanized honeybees are slower learners than their European counterparts, Naturwissenschaften 97 (2010), pp. 153-160.

130. T. Yokoi and K. Fujisaki, Recognition of scent marks in solitary bees to avoid previously visited flowers, Ecol. Res. 24 (2009), pp. 803-809.

131. A.D. Howell and R. Alarcón, Osmia bees (Hymenoptera: Megachilidae) can detect nectar-rewarding flowers using olfactory cues, Anim. Behav. 74 (2007), pp. 199-205.

132. J. Spaethe, J. Tautz, and L. Chittka, Visual constraints in foraging bumblebees: Flower size and color affect search time and flight behavior, Proc. Nat. Acad. Sci. USA 98 (2001), pp. 3898-3903.

133. M. Giurfa and M. Lehrer, Honeybee vision and floral displays: From detection to closeup recognition, in Cognitive Ecology of Pollination, L. Chittka and J.D. Thomson, eds., Cambridge University Press, Cambridge, UK, 2001, pp. 61-82.

134. L. Chittka, J. Spaethe, A. Schmidt, and A. Hickelsberger, Adaptation, constraint, and chance in the evolution of flower color and pollinator color vision, in Cognitive Ecology of Pollination, L. Chittka and J.D. Thomson, eds., Cambridge University Press, Cambridge, UK, 2001, pp. 106-126.

135. L. Chittka, A.G. Dyer, F. Bock, and A. Dornhaus, Psychophysics-Bees trade off foraging speed for accuracy, Nature 424 (2003), p. 388.

136. M. Goverde, K. Schweizer, B. Baur, and A. Erhardt, Small-scale habitat fragmentation effects on pollinator behaviour: Experimental evidence from the bumblebee Bombus veteranus on calcareous grasslands, Biol. Conserv. 104 (2002), pp. 293-299. 
137. H.E. Julier and T.H. Roulston, Wild bee abundance and pollination service in cultivated pumpkins: Farm management, nesting behavior and landscape effects, J. Econ. Entomol. 102 (2009), pp. 563-573.

138. J.H. Cane, Soils of ground-nesting bees (Hymenoptera, Apoidea)-Texture, moisture, cell depth and climate, J. Kans. Entomol. Soc. 64 (1991), pp. 406-413.

139. J. Bosch and N. Vicens, Body size as an estimator of production costs in a solitary bee, Ecol. Entomol. 27 (2002), pp. 129-137.

140. P.G. Willmer and G.N. Stone, Incidence of entomophilous pollination of lowland coffee (Coffea canephora)-The role of leaf cutter bees in Papua New Guinea, Entomol. Exp. Appl. 50 (1989), pp. 113-124.

141. R.L. Minckley, W.T. Wcislo, D. Yanega, and S.L. Buchmann, Behavior and phenology of a specialist bee (Dieunomia) and sunflower (Helianthus) pollen availability, Ecology 75 (1994), pp. 1406-1419.

142. A. Gathmann and T. Tscharntke, Foraging ranges of solitary bees, J. Anim. Ecol. 71 (2002), pp. 757-764.

143. M. Munster-Swendsen and I. Calabuig, Interaction between the solitary bee Chelostoma florisomne and its nest parasite Sapyga clavicornis-Empty cells reduce the impact of parasites, Ecol. Entomol. 25 (2000), pp. 63-70.

144. W.T. Wcislo, A. Wille, and E. Orozco, Nesting biology of tropical solitary and social sweat bees, Lasioglossum (Dialictus) figueresi Wcislo and Lasioglossum (D.) aeneiventre (Friese), Insect. Soc. 40 (1993), pp. 21-40.

145. P.G. Willmer, The role of insect water-balance in pollination ecology-Xylocopa and Calotropis, Oecologia 76 (1988), pp. 430-438.

146. A. Sih and M.S. Baltus, Patch size, pollinator behavior, and pollinator limitation in catnip, Ecology 68 (1987), pp. 1679-1690.

147. F. Van Rossum, Pollen dispersal and genetic variation in an early-successional forest herb in a peri-urban forest, Plant Biol. 11 (2009), pp. 725-737.

148. N. Vicens and J. Bosch, Nest site orientation and relocation of populations of the orchard pollinator Osmia cornuta (Hymenoptera: Megachilidae), Environ. Entomol. 29 (2000), pp. 69-75.

149. S. Wolf and R.F.A. Moritz, Foraging distance in Bombus terrestris L. (Hymenoptera: Apidae), Apidologie 39 (2008), pp. 419-427.

150. A.D. Brian, The foraging of bumble bees. Part I. Foraging behaviour, Bee World 35 (1954), pp. 61-67.

151. R Development Core Team, $R$ : A language and environment for statistical computing, 2.9.0. R Foundation for Statistical Computing, eds., Vienna, Austria, 2009. Software available at http://www.r-project.org.

152. C. O'Toole and A. Raw, Bees of the World, Facts on File, New York, 1991.

153. T.L. Pitts-Singer and J. Bosch, Nest establishment, pollination efficiency, and reproductive success of Megachile rotundata (Hymenoptera: Megachilidae) in relation to resource availability in field enclosures, Environ. Entomol. 39 (2010), pp. 149-158.

154. T. Bradley and P. Patton, Essential Mathematics for Economics and Business, 2nd edn., John Wiley \& Sons, Chichester, UK, 2002. 